\title{
Establishments Dynamics and Matching Frictions in Classical Competitive Equilibrium*
}

\author{
Marcelo Veracierto \\ Federal Reserve Bank of Chicago
}

August 2007

VERY PRELIMINARY AND INCOMPLETE

\begin{abstract}
This paper develops a Walrasian equilibrium theory of establishment level dynamics and matching frictions and uses it to evaluate the effects of congestion externalities in the matching process and determine the government interventions that are needed to implement a Pareto optimal allocation. The optimal policy, which involves a tax on the creation of help-wanted ads and an unemployment subsidy, is highly contractionary. However, it leads to large welfare gains. The policy also plays an important role in dampening the response of the economy to aggregate productivity shocks.
\end{abstract}

*This paper originated in a conversation with Randall Wright and was heavily influenced by it. I have also benefited from the comments of seminar participants at the Federal Reserve Bank of Philadelphia and the 2007 NBER Summer Institute. All remaining errors are solely mine. The views express here do not necessarily reflect the position of the Federal Reserve Bank of Chicago or the Federal Reserve System. Address: Federal Reserve Bank of Chicago, Research Department, 230 South LaSalle Street, Chicago, IL 60604. E-mail: mveracierto@frbchi.org. Phone: (312) 322-5695. 


\section{Introduction}

This paper develops a Walrasian theory of establishment level dynamics and matching frictions and uses it to evaluate the effects of congestion externalities in the matching process. The theory blends together three important strands in the literature: 1) the Hopenhayn and Rogerson [6] model of establishment dynamics, 2) the Mortensen and Pissarides [9] matching model, and 3) the Lucas and Prescott [8] islands model. In my model establishments are similar to those in Hopenhayn and Rogerson [6] except that the amount of hiring that they can undertake is determined by the number of help-wanted ads that they posted during the previous period. Similarly to Mortensen and Pissarides [9] unemployed workers and help-wanted ads meet according to a matching function. However, wages are determined by Walrasian markets instead of bilateral Nash bargaining and productions units are constituted by establishments instead of individual jobs. From the Lucas and Prescott [8] model I retain the directed search specification but assume that the search costs are incurred by the establishments instead of the unemployed workers. These modelling choices give rise to a unified framework for analyzing establishment dynamics, vacancies, unemployment and matching frictions that fully relies on classical price theory. An important goal of the paper is to evaluate if this type of framework can explain the behavior of U.S. labor markets both at growth-trend and business cycle frequencies.

The economy is populated by a representative household constituted by a continuum of members that value consumption and leisure. Household members differ in their employment histories but obtain full insurance within the household. The consumption good is produced by a large number of spatially separated establishments that operate a decreasing returns to scale technology using labor as the only input of production. The establishments are subject to idiosyncratic productivity shocks that induce them to expand and contract over time. In order to hire a worker an establishment needs to have a hiring opportunity. In the same vein, an unemployed workers needs to have a job opportunity in order to become employed. Hiring opportunities and job opportunities are jointly produced: They are obtained when an unemployed worker meets the help-wanted ad posted by an establishment. The rate at which a help-wanted ad meets unemployed workers is determined by the aggregate number of help-wanted ads and unemployed workers entering a constant returns to scale matching technology. In order to retain a Walrasian market structure I assume that any of the unemployed workers with a job opportunity can be hired by any of the establishments with a hiring opportunity. 
I analyze this economy in a number of ways. First, I solve the social planner's problem and characterize the efficient allocation. Second, I describe a competitive equilibrium that attains the Pareto optimum allocation. The decentralization requires a large number of competitive matching companies operating the constant returns to scale matching technology at a reduced scale. This equilibrium is efficient because the matching companies fully internalize the congestion effects that unemployed workers and help-wanted ads generate. Third, I describe a competitive equilibrium with matching externalities. This type of equilibrium, which is standard in the matching literature, specifies that the search technology can only be operated at the aggregate level and that establishments and unemployed workers have free access to it. Since no decision maker regulates the operation of the matching technology, congestion externalities arise and the competitive equilibrium is inefficient. Fourth, I characterize the government interventions needed to attain the Pareto optimal allocation in the competitive equilibrium with matching externalities. The optimal policy, which implements a version of Hosios' condition, involves a subsidy to unemployed workers and a tax to the creation of help-wanted ads.

The quantitative results indicate that the competitive equilibrium with congestion externalities is quite succesful in replicating the behavior of U.S. labor markets. In particular, parameter values can be chosen to reproduce important long-run establishment level observations (e.g. the size distribution of establishments, job creation and destruction rates, etc.) as well as aggregate labor market statistics (e.g. the unemployment rate, the hazard rate of unemployment, the elasticity of the hazard rate of unemployment with respect to market tightness, etc.). More importantly, when aggregate productivity shocks of empirically plausible magnitude are introduced, the model is found to replicate the observed business cycle behavior of output, employment, unemployment and vacancies. Given the empirical success of this version of the model, it becomes important to evaluate the magnitude of the congestion externalities underlying the matching process. I find that the externalities are quite large: Undoing them require a tax on help-wanted ads of $267 \%$ and a subsidy to unemployed workers equal to $4 \%$ of wages. Moreover, introducing the optimal policy reduces output by $6.2 \%$, consumption by $5.5 \%$ and employment by $9.9 \%$. Although the policy is contractionary, the increase in leisure more than compensates the drop in consumption and a steady state welfare gain of $0.8 \%$ in terms of permanent consumption is obtained. Once transitionary dynamics are considered the welfare gain increases to $1.1 \%$ in terms of consumption.

The paper is organized as follows. Section 2 describes the economy. Section 3 describes the set of feasible allocations. Section 4 characterizes a Pareto optimal allocation. Section 5 describes the 
competitive equilibrium that decentralizes the optimal allocation. Section 6 describes a competitive equilibrium with matching externalities. Section 7 characterizes the government intervention that attains the Pareto optimal allocation in a competitive equilibrium with matching externalities. Section 8 calibrates the steady state competitive equilibrium with matching externalities. Finally, Section 9 presents the results.

\section{The economy}

The economy is populated by a measure one of households, each composed by a unit interval of members called workers. Labor is indivisible: Workers can be either employed or unemployed, and employed workers must spend a larger amount of time in market activities than unemployed workers. The preferences of the representative household are given by:

$$
\sum_{t=0}^{\infty} \beta^{t}\left[\frac{c_{t}^{1-\sigma}-1}{1-\sigma}+\varphi U_{t}\right]
$$

where $c_{t}$ is consumption, $U_{t}$ is unemployment, $\varphi>0, \sigma>0$ and $0<\beta<1$. The parameter $\varphi$ is positive since the household is assumed to value leisure.

The consumption good is produced by a large number of spatially separated establishments. Each establishment has a production function given by

$$
y_{t}=s_{t} F\left(n_{t}\right)
$$

where $s_{t} \in S=\left\{0, s_{1}, s_{2}, \ldots, s_{\max }\right\}$ is an idiosyncratic productivity shock, $n_{t}$ is labor, and $F$ is a twice continuously differentiable, strictly increasing, and strictly concave function with $\lim _{n \rightarrow 0} F^{\prime}(n)=$ $+\infty$ and $\lim _{n \rightarrow \infty} F^{\prime}(n)=0$. The idiosyncratic productivity shock $s_{t}$ follows a finite Markov process with monotone transition matrix $Q$. Realizations of $s_{t}$ are assumed independent across all establishments and $s_{t}=0$ is assumed to be an absorbing state. Since there are no fixed costs of operation, exit takes place only when the idiosyncratic productivity level becomes zero. In every period, a measure $\varsigma$ of new establishments is exogenously born. Their distribution over initial productivity shocks is given by $\psi$.

Establishments can hire workers in a central island called the hiring market. However, the number of workers that an establishment can hire is constrained by the number of hiring opportunities $m_{t}$ that the establishment has available at the beginning of the period. An establishment receives 
a hiring opportunity when one of its posted help-wanted ads meets an unemployed worker. Since workers are assumed to quit at the exogenous rate $\delta$, an establishment's employment level $n_{t}$ is constrained as follows:

$$
n_{t} \leq(1-\delta) n_{t-1}+m_{t}
$$

All workers that separate from an establishment (either because of quits or firings) join the pool of unemployment.

Unemployed workers have the possibility of becoming employed in the hiring market, but only if they have a job opportunity. An unemployed worker receives a job opportunity when he meets a help-wanted ad posted by some establishment. Once in the hiring market, any unemployed worker with a job opportunity can be hired by any establishment with a hiring opportunity.

The matching technology, which jointly produces job and hiring opportunities, is described as follows. Let $A_{t}$ be the total number of help-wanted ads in the matching technology, and let $U_{t}$ be the total number of unemployed workers in the matching technology. The number of hiring opportunities obtained by an establishment that created $a_{t}$ help-wanted ads is given by:

$$
m_{t+1}=a_{t} m\left(A_{t}, U_{t}\right)
$$

where $m$ is assumed to be strictly concave, strictly decreasing in $A$, strictly increasing in $U$ and homogeneous of degree zero. The total number of job opportunities obtained by unemployed workers is then equal to

$$
M_{t+1}=M\left(A_{t}, U_{t}\right)
$$

i.e. it is given by the total number of hiring opportunities

\section{Feasibility}

In what follows, it will be convenient to index establishments by the date $j$ of their creation, by their history of idiosyncratic shocks $s_{j}^{t}=\left(s_{j}, s_{j+1} \ldots, s_{t-1}, s_{t}\right) \in S^{t-j+1}$ since the date of their creation and by the number of workers $e$ that they were endowed with at the time of their creation. Only establishments created at $t=0$ are allowed to have a positive initial endowment of workers $e$. Establishments created after $t=0$ have a zero initial endowment of workers. ${ }^{1}$

\footnotetext{
${ }^{1}$ The "initial endowment" variable $e$ is introduced to avoid carrying separate notation for incumbent establishments at $t=0$ and establishments created after $t=0$.
} 
The number of establishments $\mu_{0}\left(0, s_{0}, e\right)$ created at $t=0$ with initial productivity $s_{0}$ and initial endowment of workers $e$, is given. For $t \geq 1$, the number of establishments $\mu_{t}\left[j, s_{j}^{t}, e\right]$ with creation date $j \leq t$, history $s_{j}^{t}$ and initial endowment of workers $e$ satisfies the following equations:

$$
\begin{aligned}
\mu_{t}\left(t, s_{t}, 0\right) & =\varsigma \psi\left(s_{t}\right), \\
\mu_{t}\left(t, s_{t}, e\right) & =0, \text { for } e>0, \\
\mu_{t}\left[j,\left(s_{j}, s_{j+1} \ldots, s_{t-1}, s_{t}\right), e\right] & =\mu_{t-1}\left[j,\left(s_{j}, s_{j+1} \ldots, s_{t-1}\right), e\right] Q\left(s_{t-1}, s_{t}\right), \text { for } 0 \leq j<t .
\end{aligned}
$$

Aggregate consumption is given by

$$
c_{t} \leq \sum_{j=0}^{t} \sum_{s_{j}^{t}} \sum_{e}\left[s_{t} F\left[n_{t}\left(j, s_{j}^{t}, e\right)\right]-k a_{t}\left(j, s_{j}^{t}, e\right)\right] \mu_{t}\left(j, s_{j}^{t}, e\right)
$$

where $a_{t}\left(j, s_{j}^{t}, e\right)$ are the help-wanted ads created by an establishment of type $\left(j, s_{j}^{t}, e\right)$. This equation states that aggregate consumption is equal to the sum of output net of help-wanted ad costs across all types of establishments.

Aggregate help-wanted ads are given by:

$$
\sum_{j=0}^{t} \sum_{s_{j}^{t}} \sum_{e} a_{t}\left(j, s_{j}^{t}, e\right) \mu_{t}\left(j, s_{j}^{t}, e\right) \leq A_{t}
$$

i.e. it is the sum of help-wanted ads across all type of establishments. Unemployment is given by:

$$
U_{t} \leq 1-\sum_{j=0}^{t} \sum_{s_{j}^{t}} \sum_{e} n_{t}\left(j, s_{j}^{t}, e\right) \mu_{t}\left(j, s_{j}^{t}, e\right)
$$

i.e. it is the total number of agents that do not work.

Employment feasibility at the establishment level is described as follows. For $j=t$,

$$
n_{t}\left(j, s_{j}^{t}, e\right) \leq e
$$

since at the time of their creation establishments cannot employ more than their initial endowment of workers. For $j<t$ :

$$
n_{t}\left(j, s_{j}^{t}, e\right) \leq(1-\delta) n_{t-1}\left(j, s_{j}^{t-1}, e\right)+a_{t-1}\left(j, s_{j}^{t-1}, e\right) m\left[A_{t-1}, U_{t-1}\right]
$$


That is, the employment level of an establishment cannot exceed the sum of its previous employment level net of quits and the number of hiring opportunities that it has at the beginning of the period.

\section{Pareto optimal allocations}

The social planner's problem is to maximize (2.1) subject to equations (3.1)-(3.5). Since the utility function in equation (2.1), the production function $F$ and the matching function $M$ are concave, this is a standard problem. An analysis of its first order conditions leads to the following characterization.

An efficient allocation can be described by a sequence $\left\{c_{t}, A_{t}, U_{t}, v_{t}, n_{t}, a_{t}, \theta_{t}, \gamma_{t}, \mu_{t}\right\}_{t=0}^{\infty}$. The elements $v_{t}, n_{t}$, and $a_{t}$ are functions of the state of an establishment $(x, s)$, where $x$ are the units of labor available for employment at the beginning of the period and $s$ is the current productivity level. The number $v_{t}(x, s)$ is the date $t$ shadow value of a worker at an establishment of type $(x, s)$, the number $n_{t}(x, s)$ is the date $t$ employment level at an establishment of type $(x, s)$, and the number $a_{t}(x, s)$ are the date $t$ help-wanted ads created by an establishment of type $(x, s)$. The elements $\theta_{t}$ and $\gamma_{t}$ are numbers: $\theta_{t}$ is the date $t$ shadow value of a worker in the pool of aggregate unemployment and $\gamma_{t}$ is the shadow value of a next-period hiring opportunity. ${ }^{2}$ Finally, the element $\mu_{t}$ is the date $t$ measure of establishments across states $(x, s)$. To represent an efficient allocation, the sequence must satisfy the following conditions.

The shadow value of a worker at an establishment of type $(x, s)$ must satisfy the following equation:

$$
\begin{aligned}
v_{t}(x, s)= & \max \left\{\theta_{t}, s F^{\prime}(x)+\beta\left(\frac{c_{t}}{c_{t+1}}\right)^{\sigma} \delta \theta_{t+1}\right. \\
& \left.+\beta\left(\frac{c_{t}}{c_{t+1}}\right)^{\sigma}(1-\delta) \sum_{s^{\prime}} v_{t+1}\left[(1-\delta) x+a_{t}(x, s) m\left[A_{t}, U_{t}\right], s^{\prime}\right] Q\left(s, s^{\prime}\right)\right\} .
\end{aligned}
$$

This equation is quite intuitive. The shadow value $v_{t}(x, s)$ cannot be less than the social value of sending an additional worker to the pool of unemployment $\theta_{t}$. Otherwise, welfare could be improved by reducing the employment level of the establishment. If the shadow value $v_{t}(x, s)$ exceeds the value of unemployment, the planner retains all workers available to the establishment $x$. In this case, the flow shadow value of a worker is given by the marginal productivity $s F^{\prime}(x)$.

\footnotetext{
${ }^{2}$ All shadow values are expressed in terms of the consumption good.
} 
With probability $\delta$ the worker quits and his continuation value is the discounted shadow value $\theta_{t+1}$ of having an additional worker in the pool of unemployment at the beginning of the following period. With probability $(1-\delta)$ the worker does not quit the following period, and his continuation value is equal to the expected discounted shadow value $v_{t+1}$ of beginning the following period in an establishment with $(1-\delta) x+a_{t}(x, s) m\left[A_{t}, U_{t}\right]$ workers available for employment. Observe that the social planner discounts next period values using the product of the discount factor $\beta$ and the intertemporal marginal rate of substitution $\left(c_{t} / c_{t+1}\right)^{\sigma}$.

The optimal number of help-wanted ads created by an establishment of type $(x, s)$ is characterized by the following condition:

$$
\begin{gathered}
\beta\left(\frac{c_{t}}{c_{t+1}}\right)^{\sigma} \sum_{s^{\prime}} v_{t+1}\left[(1-\delta) n_{t}(x, s)+a_{t}(x, s) m\left(A_{t}, U_{t}\right), s^{\prime}\right] Q\left(s, s^{\prime}\right) \leq \gamma_{t}+\beta\left(\frac{c_{t}}{c_{t+1}}\right)^{\sigma} \theta_{t+1} \\
\text { with equality if } a_{t}(x, s)>0 .
\end{gathered}
$$

That is, if the establishment creates a positive number of help-wanted ads it must be the case that the expected discounted shadow value of a worker at the establishment $v_{t+1}$ is equal to the shadow value of a next-period hiring opportunity $\gamma_{t}$ plus the discounted shadow value of a nextperiod unemployed worker $\theta_{t+1}$. This conditions is also intuitive. If $\beta\left(c_{t} / c_{t+1}\right)^{\sigma} E\left[v_{t+1}\right]>\gamma_{t}+$ $\beta\left(c_{t} / c_{t+1}\right)^{\sigma} \theta_{t+1}$, the value of increasing the establishment's next-period hiring opportunities by one unit exceeds the opportunity cost. As a consequence, welfare could be improved by realizing this increase. If $\beta\left(c_{t} / c_{t+1}\right)^{\sigma} E\left[v_{t+1}\right]<\gamma_{t}+\beta\left(c_{t} / c_{t+1}\right)^{\sigma} \theta_{t+1}$ even when zero hiring opportunities are created, the social planner stays at the corner solution of $a_{t}(x, s)=0$.

Substitution equation (4.2) in equation (4.1) gives

$$
\begin{aligned}
v_{t}(x, s)= & \max \left\{\theta_{t}, s F^{\prime}(x)+\delta \beta\left(\frac{c_{t}}{c_{t+1}}\right)^{\sigma} \theta_{t+1}\right. \\
& \left.+(1-\delta) \min \left[\beta\left(\frac{c_{t}}{c_{t+1}}\right)^{\sigma} \sum_{s^{\prime}} v_{t+1}\left[(1-\delta) x, s^{\prime}\right] Q\left(s, s^{\prime}\right), \gamma_{t}+\beta\left(\frac{c_{t}}{c_{t+1}}\right)^{\sigma} \theta_{t+1}\right]\right\} .
\end{aligned}
$$

The optimal employment rule $n_{t}(x, s)$ is then easily obtained. It is characterized by a threshold level $\bar{x}_{t}(s)$ that satisfies the following condition:

$$
\begin{aligned}
\theta= & s F^{\prime}\left(\bar{x}_{t}(s)\right)+\delta \beta\left(\frac{c_{t}}{c_{t+1}}\right)^{\sigma} \theta_{t+1} \\
& +(1-\delta) \min \left\{\beta\left(\frac{c_{t}}{c_{t+1}}\right)^{\sigma} \sum_{s^{\prime}} v_{t+1}\left[(1-\delta) \bar{x}_{t}(s), s^{\prime}\right] Q\left(s, s^{\prime}\right), \gamma_{t}+\beta\left(\frac{c_{t}}{c_{t+1}}\right)^{\sigma} \theta_{t+1}\right\} .
\end{aligned}
$$


That is, $\bar{x}_{t}(s)$ is the unique value of $x$ at which the social planner is indifferent between leaving the marginal worker at the establishment and sending him to the pool of unemployment.

The optimal employment rule is then given by:

$$
n_{t}(x, s)=\min \left\{\bar{x}_{t}(s), x\right\}
$$

That is, if $x>\bar{x}_{t}(s)$, the shadow value of a worker in an establishment of type $(x, s)$ is less than the shadow value of unemployment. As a consequence, the social planner reduces the employment level of the establishment to the point at which he is indifferent between making a further reduction in employment or not.

The optimal help-wanted ads creation rule $a_{t}(x, s)$ is also easily obtained. It is characterized by a threshold level $\underline{x}_{t}(s)$ that satisfies the following condition:

$$
\beta\left(\frac{c_{t}}{c_{t+1}}\right)^{\sigma} \sum_{s^{\prime}} v_{t+1}\left[(1-\delta) \underline{x}_{t}(s), s^{\prime}\right] Q\left(s, s^{\prime}\right)=\gamma_{t}+\beta\left(\frac{c_{t}}{c_{t+1}}\right)^{\sigma} \theta_{t+1}
$$

The help-wanted ads creation rule is then given by

$$
a_{t}(x, s) m\left(A_{t}, U_{t}\right)=\left\{\begin{array}{c}
0, \text { if } \min \left\{\bar{x}_{t}(s), x\right\}>\underline{x}_{t}(s) \\
(1-\delta)\left[\underline{x}_{t}(s)-\min \left\{\bar{x}_{t}(s), x\right\}\right], \text { otherwise }
\end{array}\right\} .
$$

The shadow value of a next-period hiring opportunity $\gamma_{t}$ satisfies the following condition:

$$
\gamma_{t}=\frac{k}{m\left(A_{t}, U_{t}\right)+A_{t} m_{A}\left(A_{t}, U_{t}\right)}
$$

Observe that $m+A \cdot m_{A}>0$ is the marginal product of a help-wanted ad in creating next-period hiring opportunities. Since $k$ is the cost of creating a help-wanted ad, equation (4.7) states that the shadow value of a next-period hiring opportunity equals its cost of production.

The shadow value of an unemployed worker $\theta_{t}$ is given by

$$
\theta_{t}=c_{t}^{\sigma} \varphi+\gamma_{t} A_{t} m_{U}\left(A_{t}, U_{t}\right)+\beta\left(\frac{c_{t}}{c_{t+1}}\right)^{\sigma} \theta_{t+1}
$$

Observe that $A m_{U}$ is the marginal product of an unemployed worker in creating next-period hiring opportunities, which are valued at the shadow price $\gamma_{t}$. Thus equation (4.8) states that the shadow value of an unemployed worker $\theta_{t}$ is equal to his value of leisure expressed in consumption units 
$c_{t}^{\sigma} \varphi$, plus his shadow value in creating next period hiring opportunities $\gamma_{t} A_{t} m_{U}$, plus the discounted shadow value of being an unemployed worker during the following period.

Consumption $c_{t}$ is given by

$$
c_{t}=\sum_{s}\left[s_{t} F\left[n_{t}(x, s)\right]-k a_{t}(x, s)\right] \mu_{t}(d x, s),
$$

aggregate help-wanted ads $A_{t}$ are given by

$$
A_{t}=\sum_{s} a_{t}(x, s) \mu_{t}(d x, s)
$$

and aggregate unemployment $U_{t}$ is

$$
U_{t}=1-\sum_{s} n_{t}(x, s) \mu_{t}(d x, s)
$$

Finally, the sequence of measures $\mu_{t}$ must satisfy

$$
\mu_{t+1}\left(X^{\prime}, s^{\prime}\right)=\sum_{s} \int_{B_{t}(s)} Q\left(s, s^{\prime}\right) d \mu_{t}+\varsigma \psi\left(s^{\prime}\right) I\left(X^{\prime}\right)
$$

where $I\left(X^{\prime}\right)$ is an indicator function that takes a value equal to one if $0 \in X^{\prime}$ and a value of zero, otherwise, and $B_{t}(s)$ is the set of all $x$ such that $(1-\delta) x+a_{t}(x, s) m\left(A_{t}, U_{t}\right)$ lies in the Borel set $X^{\prime}$.

An efficient allocation is a sequence $\left\{c_{t}, A_{t}, U_{t}, v_{t}, n_{t}, a_{t}, \theta_{t}, \gamma_{t}, \mu_{t}\right\}_{t=0}^{\infty}$ such that equations (4.1)(4.12) hold, with $\mu_{0}$ given. Observe that, from the concavity of the planner's problem, a unique efficient allocation exists.

\section{A competitive equilibrium}

In what follows I specify a competitive equilibrium in which workers are bought and sold as capital goods. ${ }^{3}$ Establishments buy workers in the hiring market, sell them in the firing market and buy hiring opportunities from matching companies. Households buy workers in the firing market, sell them in the hiring market, rent unemployed workers to the matching companies, and receive

\footnotetext{
${ }^{3}$ I choose this unusual specification because it easy to describe. It turns out that it is equivalent to a much more complicated specification in which households and establishments trade binding state contingent employment contracts (see Alvarez and Veracierto [1] for this alternative formulation).
} 
job-opportunities for free. Since at every period of time, there is always some positive number of establishments that do not use all the hiring opportunities available to them (because their productivity shocks have changed), the price of a worker in the hiring market is always brought down to the price in the firing market. Hereon, I will refer to this single price as the price of $a$ worker $p_{t}^{w}$ in the labor market.

The date $t$ problem of an establishment that has $e$ workers carried over from the previous period, $m$ hiring opportunities and current productivity level $s$ is given by:

$$
\begin{aligned}
J_{t}(e, m, s)= & \max _{n_{t}, m_{t+1}, h_{t}, f_{t}}\left\{s F\left(n_{t}\right)+p_{t}^{w}\left(f_{t}-h_{t}\right)-q_{t}^{h} m_{t+1}\right. \\
& \left.+\frac{1}{1+i_{t}} \sum_{s^{\prime}} J_{t+1}\left[(1-\delta) n_{t}, m_{t+1}, s^{\prime}\right] Q\left(s, s^{\prime}\right)+\frac{1}{1+i_{t}} p_{t+1}^{w} \delta n_{t}\right\}
\end{aligned}
$$

subject to

$$
\begin{aligned}
& n_{t}=e+h_{t}-f_{t} \\
& h_{t} \leq m
\end{aligned}
$$

where $p_{t}^{w}$ is the price of a worker, $q_{t}^{h}$ is the price of a hiring opportunity in the next period, $n_{t}$ is the employment level of the establishment, $h_{t}$ is the amount of hiring, $f_{t}$ is the amount of firing, $m_{t+1}$ is the number of hiring opportunities that the establishment purchases, $i_{t}$ is the interest rate, and $J_{t}(e, m, s)$ is the present expected discounted value at date $t$ of an establishment of type $(e, m, s)$ after quits have taken place. Observe that an establishment maximizes the present discounted value of its profits, which are given by the sum of its output and its net sale of workers, minus the value of the hiring opportunities that the establishment buys in the matching market. Also observe that the amount of hiring cannot exceed the number of hiring opportunities available at the beginning of the period.

It is straightforward to show that $J_{e t}=J_{m t}+p_{t}^{w}$. Moreover, $J_{e t}$ and $J_{m t}$ depend on $(e, m)$ only through the sum $x=e+m$. Using these properties, the first order conditions for the establishment's problem can be written as follows:

$$
\begin{aligned}
J_{e t}(x, s)= & \max \left\{p_{t}^{w}, s F^{\prime}(x)+\frac{1}{1+i_{t}} p_{t+1}^{w} \delta\right. \\
& \left.+(1-\delta) \frac{1}{1+i_{t}} \sum_{s^{\prime}} J_{e, t+1}\left[(1-\delta) x+m_{t+1}(x, s), s^{\prime}\right] Q\left(s, s^{\prime}\right)\right\},
\end{aligned}
$$


and

$$
\begin{aligned}
\frac{1}{1+i_{t}} \sum_{s^{\prime}} J_{e, t+1}\left[(1-\delta) n_{t}(x, s)+m_{t+1}(x, s), s^{\prime}\right] Q\left(s, s^{\prime}\right) & \leq q_{t}^{h}+\frac{1}{1+i_{t}} p_{t+1}^{w}, \\
\text { with equality if } m_{t+1}(x, s) & >0 .
\end{aligned}
$$

The establishment's employment rule $n_{t}(x, s)$ is similar to that of the social planner. It is characterized by a threshold level $\bar{x}_{t}(s)$ that satisfies the following condition:

$$
\begin{aligned}
p_{t}^{w}= & s F^{\prime}\left(\bar{x}_{t}(s)\right)+\frac{1}{1+i_{t}} p_{t+1}^{w} \delta \\
& +(1-\delta) \min \left[\frac{1}{1+i_{t}} \sum_{s^{\prime}} J_{e, t+1}\left[(1-\delta) \bar{x}_{t}(s), s^{\prime}\right] Q\left(s, s^{\prime}\right), q_{t}^{h}+\frac{1}{1+i_{t}} p_{t+1}^{w}\right]
\end{aligned}
$$

The optimal employment rule is then given by

$$
n_{t}(x, s)=\min \left\{\bar{x}_{t}(s), x\right\}
$$

The optimal hiring opportunities creation rule is also easily obtained. It is characterized by a threshold level $\underline{x}_{t}(s)$ that satisfies the following condition:

$$
\frac{1}{1+i_{t}} \sum_{s^{\prime}} J_{e, t+1}\left[(1-\delta) \underline{x}_{t}(s), s^{\prime}\right] Q\left(s, s^{\prime}\right)=q_{t}^{h}+\frac{1}{1+i_{t}} p_{t+1}^{w} .
$$

The hiring opportunities creation rule is given by

$$
m_{t+1}(x, s)=\left\{\begin{array}{c}
0, \text { if } \min \left\{\bar{x}_{t}(s), x\right\}>\underline{x}_{t}(s) \\
(1-\delta)\left[\underline{x}_{t}(s)-\min \left\{\bar{x}_{t}(s), x\right\}\right], \text { otherwise }
\end{array}\right\}
$$

The problem of a household that had $u_{t-1}$ unemployed workers during the previous period and that during the current period has $j_{t}$ job opportunities and $b_{t}$ bond holdings is the following:

$$
H_{t}\left(u_{t-1}, j_{t}, b_{t}\right)=\max \left\{\frac{c_{t}^{1-\sigma}-1}{1-\sigma}+\varphi u_{t}+\beta H_{t+1}\left(u_{t}, j_{t+1}, b_{t+1}\right)\right\}
$$


subject to

$$
\begin{aligned}
c_{t}+b_{t+1} & \leq p_{t}^{m} u_{t}+p_{t}^{w}\left(h_{t}-f_{t}\right)+\left(1+i_{t-1}\right) b_{t}+\Pi_{t} \\
u_{t} & =\left(u_{t-1}-j_{t}\right)+f_{t}+\left(j_{t}-h_{t}\right) \\
h_{t} & \leq j_{t} \\
f_{t} & \leq 1-u_{t-1} \\
j_{t+1} & =u_{t} \frac{M_{t+1}}{U_{t}}
\end{aligned}
$$

where $u_{t}$ is the number of unemployed members during the current period, $h_{t}$ are the household members sold in the hiring market, $f_{t}$ are the household members bought in the firing market and $\Pi_{t}$ are the profits of all the establishments in the economy. The first constraint is the household's budget constraint. Observe that the household receives income from renting unemployed members to the matching companies $p_{t}^{m} u_{t}$, from the selling of workers in the hiring market $p_{t}^{w} h_{t}$, from interest and principal payments on its bond holdings $\left(1+i_{t-1}\right) b_{t}$ and from the establishments' profits $\Pi_{t}$. The household spends its income in purchasing workers in the firing market $p_{t}^{w} f_{t}$, on consumption $c_{t}$ and on next period bond holdings $b_{t+1}$. The second constraint states that the number of unemployed members during the current period $u_{t}$ is given by the number of unemployed members in the previous period that were left unmatched $u_{t-1}-j_{t}$, by the household members bought in the firing market $f_{t}$, and by the household members left unsold in the hiring market $j_{t}-h_{t}$. The third constraint states that the number of household members sold in the hiring market $h_{t}$ cannot exceed the job-opportunities available to the household at the beginning of the period $j_{t}$. The fourth constraint states that the number of household members bought in the firing market $f_{t}$ cannot exceed the number of household members that were employed during the previous period $1-u_{t-1}$. The last constraint states that the number of job opportunities that the household will have the following period is given by the number of unemployed members during the current period times the rate at which the representative firm creates job-opportunities.

Observe that the third and fourth constraints must hold with strict inequality at equilibrium. For these constraints not to bind, the household must view its problem as being independent of its job-opportunities $j_{t}$. This requires that

$$
p_{t}^{w}=c_{t}^{\sigma} \varphi+p_{t}^{m}+\beta\left(\frac{c_{t}}{c_{t+1}}\right)^{\sigma} p_{t+1}^{w}
$$


This condition states that the household must be indifferent between selling workers in the hiring market and keeping them unemployed. The left hand side is the price $p_{t}^{w}$ that the household can get by selling an unemployed worker in the hiring market. The right hand side is the sum of the value of leisure expressed in consumption units $c_{t}^{\sigma} \varphi$, the rental price of an unemployed worker in the matching industry $p_{t}^{m}$, and the savings from buying one less unemployed worker in the firing market at the beginning of the following period (expressed in current consumption units) $\beta\left(\frac{c_{t}}{c_{t+1}}\right)^{\sigma} p_{t+1}^{w}$. Also observe that the solution to the household's problem requires that

$$
\frac{1}{1+i_{t}}=\beta\left(\frac{c_{t}}{c_{t+1}}\right)^{\sigma}
$$

i.e. that the interest rate be equal to the marginal rate of substitution between current consumption and future consumption.

The date $t$ problem of the representative matching company is given by:

$$
\max \left\{q_{t}^{h} M_{t+1}-p_{t}^{m} U_{t}-k A_{t}\right\}
$$

subject to

$$
M_{t+1}=A_{t} m\left(A_{t}, U_{t}\right) .
$$

That is, the matching company obtains revenues $q_{t}^{h} M_{t+1}$ from selling next period hiring opportunities, pays $p_{t}^{m} U_{t}$ for renting unemployed workers and pays $k A_{t}$ for creating help-wanted ads. The first order conditions to this problem are the following:

$$
\begin{aligned}
q_{t}^{h}\left[m\left(A_{t}, U_{t}\right)+A_{t} m_{A}\left(A_{t}, U_{t}\right)\right] & =k, \\
q_{t}^{h} A_{t} m_{U}\left(A_{t}, U_{t}\right) & =p_{t}^{m} .
\end{aligned}
$$

The first equation states that the marginal revenue product of a help-wanted ad equals its marginal cost $k$. The second equation states that the marginal revenue product of an unemployed worker equals its marginal cost $p_{t}^{m}$.

A competitive equilibrium is a sequence $\left\{c_{t}, b_{t}, A_{t}, U_{t}, J_{e t}, n_{t}, a_{t}, m_{t+1}, p_{t}^{w}, q_{t}^{h}, p_{t}^{m}, i_{t}, \mu_{t}\right\}_{t=0}^{\infty}$ such that $b_{t}=0$,

$$
a_{t}(x, s)=\frac{m_{t+1}(x, s)}{m\left(A_{t}, U_{t}\right)}
$$


and equations (5.2)-(5.11) and (4.9)-(4.12) are satisfied every period $t$, with $\mu_{0}$ given.

The following proposition states that every competitive equilibrium allocation is efficient.

Proposition 5.1. (First Welfare Theorem) Let $\left\{c_{t}, b_{t}, A_{t}, U_{t}, J_{e t}, n_{t}, a_{t}, m_{t+1}, p_{t}^{w}, q_{t}^{h}, p_{t}^{m}, i_{t}, \mu_{t}\right\}_{t=0}^{\infty}$ be a competitive equilibrium. Let

$$
\begin{aligned}
& \theta_{t}=p_{t}^{w}, \\
& v_{t}=J_{e t}, \\
& \gamma_{t}=q_{t}^{h} .
\end{aligned}
$$

Then, $\left\{c_{t}, A_{t}, U_{t}, v_{t}, n_{t}, a_{t}, \theta_{t}, \gamma_{t}, \mu_{t}\right\}_{t=0}^{\infty}$ is an efficient allocation.

Since there is a unique efficient allocation, a corollary of this proposition is that there is a unique competitive equilibrium. The following proposition states that the Second Welfare Theorem also holds.

Proposition 5.2. (Second Welfare Theorem) Let $\left\{c_{t}, A_{t}, U_{t}, v_{t}, n_{t}, a_{t}, \theta_{t}, \gamma_{t}, \mu_{t}\right\}_{t=0}^{\infty}$ be an efficient allocation. Let

$$
\begin{aligned}
p_{t}^{w} & =\theta_{t}, \\
q_{t}^{h} & =\gamma_{t}, \\
p_{t}^{m} & =\gamma_{t} A_{t} m_{U}\left(A_{t}, U_{t}\right) \\
J_{e t} & =v_{t} \\
m_{t+1}(x, s) & =a_{t}(x, s) m\left(A_{t}, U_{t}\right) \\
b_{t} & =0 \\
\frac{1}{1+i_{t}} & =\beta\left(\frac{c_{t}}{c_{t+1}}\right)^{\sigma}
\end{aligned}
$$

Then, $\left\{c_{t}, b_{t}, A_{t}, U_{t}, J_{e t}, n_{t}, a_{t}, m_{t+1}, p_{t}^{w}, q_{t}^{h}, p_{t}^{m}, i_{t}, \mu_{t}\right\}_{t=0}^{\infty}$ is a competitive equilibrium.

Both propositions follow from comparing first order conditions for the social planner's problem and the competitive equilibrium. 


\section{A competitive equilibrium with congestion externalities}

This section describes the standard notion of equilibrium considered by the matching literature: One in which the matching process is subject to congestion externalities. In particular, the matching technology is now assumed to operate only at the aggregate level. Moreover, all help-wanted ads and all unemployed workers in the economy are assumed to be inputs to it. Since no decision maker internalizes the operation of the matching technology, standard congestion externalities arise. Establishments buy workers in the hiring market, sell them in the firing market and buy help-wanted ads from job-posting companies. Households buy workers in the firing market and sell them in the hiring market. Since not all hiring opportunities are used in equilibrium, the price of a worker $p_{t}^{w}$ must be the same in the hiring market and in the firing market.

The date $t$ problem of an establishment that has $e$ workers carried over from the previous period, $m$ hiring opportunities and current productivity level $s$ is given by

$$
\begin{aligned}
J_{t}(e, m, s)= & \max _{n_{t}, h_{t}, f_{t}, a_{t}}\left\{s F\left(n_{t}\right)+p_{t}^{w}\left(f_{t}-h_{t}\right)-p_{t}^{a} a_{t}\right. \\
& \left.+\frac{1}{1+i_{t}} \sum_{s^{\prime}} J_{t+1}\left[(1-\delta) n_{t}, m_{t+1}, s^{\prime}\right] Q\left(s, s^{\prime}\right)+\frac{1}{1+i_{t}} p_{t+1}^{w} \delta n_{t}\right\}
\end{aligned}
$$

subject to

$$
\begin{aligned}
n_{t} & =e+h_{t}-f_{t} \\
h_{t} & \leq m \\
m_{t+1} & =a_{t} m\left(A_{t}, U_{t}\right)
\end{aligned}
$$

where $h_{t}$ is the number of workers bought in the hiring market, $f_{t}$ is the number of workers sold in the firing market, $a_{t}$ is the number of help-wanted ads purchased, $p_{t}^{a}$ is the price of a help-wanted ad, $i_{t}$ is the interest rate and $m_{t+1}$ is the number of hiring opportunities that the establishment generates. Observe that the number of hiring opportunities that the establishment generates $m_{t+1}$ is proportionate to the number of help-wanted ads purchased $a_{t}$, with constant of proportionality given by the aggregate effectiveness of help-wanted ads in generating hiring opportunities $m\left(A_{t}, U_{t}\right)$. The establishment takes $A_{t}$ and $U_{t}$ as given. Also, observe that the amount of hiring $h_{t}$ cannot exceed the hiring opportunities available to the establishment at the beginning of the period.

It is straightforward to show that $J_{e t}=J_{m t}+p_{t}^{w}$. Moreover, $J_{e t}$ and $J_{m t}$ depend on $(e, m)$ only 
through the sum $x=e+m$. Using these properties, the first order conditions for the establishment's problem can be written as follows:

$$
\begin{aligned}
J_{e t}(x, s)= & \max \left\{p_{t}^{w}, s F^{\prime}(x)+\frac{1}{1+i_{t}} p_{t+1}^{w} \delta\right. \\
& \left.+(1-\delta) \frac{1}{1+i_{t}} \sum_{s^{\prime}} J_{e, t+1}\left[(1-\delta) x+a_{t}(x, s) m\left(A_{t}, U_{t}\right), s^{\prime}\right] Q\left(s, s^{\prime}\right)\right\}
\end{aligned}
$$

and

$$
\begin{aligned}
\frac{1}{1+i_{t}} \sum_{s^{\prime}} J_{e, t+1}\left[(1-\delta) n_{t}(x, s)+a_{t}(x, s) m\left(A_{t}, U_{t}\right), s^{\prime}\right] Q\left(s, s^{\prime}\right) & \leq \frac{p_{t}^{a}}{m\left(A_{t}, U_{t}\right)}+\frac{1}{1+i_{t}} p_{t+1}^{w} \\
\text { with equality if } a_{t}(x, s) & >0 .
\end{aligned}
$$

The establishment's employment rule $n_{t}(x, s)$ has the same form as in the previous sections. It is characterized by a threshold level $\bar{x}_{t}(s)$ that satisfies the following condition:

$$
\begin{aligned}
p_{t}^{w}= & s F^{\prime}\left(\bar{x}_{t}(s)\right)+\frac{1}{1+i_{t}} p_{t+1}^{w} \delta \\
& +(1-\delta) \min \left[\frac{1}{1+i_{t}} \sum_{s^{\prime}} J_{e, t+1}\left[(1-\delta) \bar{x}_{t}(s), s^{\prime}\right] Q\left(s, s^{\prime}\right), \frac{p_{t}^{a}}{m\left(A_{t}, U_{t}\right)}+\frac{1}{1+i_{t}} p_{t+1}^{w}\right]
\end{aligned}
$$

The optimal employment rule is then given by

$$
n_{t}(x, s)=\min \left\{\bar{x}_{t}(s), x\right\}
$$

The optimal hiring opportunities creation rule also has the same form as before. It is characterized by a threshold level $\underline{x}_{t}(s)$ that satisfies the following condition:

$$
\frac{1}{1+i_{t}} \sum_{s^{\prime}} J_{e, t+1}\left[(1-\delta) \underline{x}_{t}(s), s^{\prime}\right] Q\left(s, s^{\prime}\right)=\frac{p_{t}^{a}}{m\left(A_{t}, U_{t}\right)}+\frac{1}{1+i_{t}} p_{t+1}^{w}
$$

The help-wanted ads creation rule is given by

$$
a_{t}(x, s) m\left(A_{t}, U_{t}\right)=\left\{\begin{array}{c}
0, \text { if } \min \left\{\bar{x}_{t}(s), x\right\}>\underline{x}_{t}(s) \\
(1-\delta)\left[\underline{x}_{t}(s)-\min \left\{\bar{x}_{t}(s), x\right\}\right], \text { otherwise }
\end{array}\right\} .
$$


The representative job-posting company solves the following static profit maximization problem:

$$
\max \left\{p_{t}^{a} A_{t}-k A_{t}\right\}
$$

where $p_{t}^{a}$ is the price of a help-wanted ad, $k$ is the cost of producing a help-wanted ad, and $A_{t}$ are the total help-wanted ads produced. Thus, at equilibrium we must have that

$$
p_{t}^{a}=k
$$

The date $t$ problem of a household that had $u_{t-1}$ unemployed workers during the previous period and that during the current period has $j_{t}$ job opportunities and $b_{t}$ bond holdings is given by

$$
H_{t}\left(u_{t-1}, j_{t}, b_{t}\right)=\max \left\{\frac{c_{t}^{1-\sigma}-1}{1-\sigma}+\varphi u_{t}+\beta H_{t+1}\left(u_{t}, j_{t+1}, b_{t+1}\right)\right\}
$$

subject to

$$
\begin{aligned}
c_{t}+b_{t+1} & \leq p_{t}^{w}\left(h_{t}-f_{t}\right)+\left(1+i_{t-1}\right) b_{t}+\Pi_{t} \\
u_{t} & =\left(u_{t-1}-j_{t}\right)+f_{t}+\left(j_{t}-h_{t}\right) \\
h_{t} & \leq j_{t} \\
f_{t} & \leq 1-u_{t-1} \\
j_{t+1} & =u_{t} \frac{M_{t+1}}{U_{t}}
\end{aligned}
$$

where $u_{t}$ is the number of unemployed members during the current period, $h_{t}$ are the household members sold in the hiring market, $f_{t}$ are the household members bought in the firing market, and $\Pi_{t}$ are the profits of all the establishments in the economy. The household takes the aggregate effectiveness at which unemployed workers reach the hiring market. $M_{t+1} / U_{t}$ as given. Observe that the third and fourth constraints must hold with strict inequality at equilibrium. For these constraints to be non-binding at every period $t$, the household must view its problem as being independent of its job-opportunities $j_{t}$. This requires that

$$
p_{t}^{w}=c_{t}^{\sigma} \varphi+\beta\left(\frac{c_{t}}{c_{t+1}}\right)^{\sigma} p_{t+1}^{w}
$$

for every $t$. This condition states that the household must be indifferent between selling workers in 
the hiring market and keeping them unemployed. Also observe that the solution to the household's problem requires that

$$
\frac{1}{1+i_{t}}=\beta\left(\frac{c_{t}}{c_{t+1}}\right)^{\sigma}
$$

A competitive equilibrium with congestion externalities is a sequence $\left\{c_{t}, b_{t}, A_{t}, U_{t}, J_{e t}, n_{t}, a_{t}\right.$, $\left.p_{t}^{w}, p_{t}^{a}, i_{t}, \mu_{t}\right\}_{t=0}^{\infty}$ such that $b_{t}=0$ and equations (6.1)-(6.9) and (4.9)-(4.12) are satisfied every period $t$, with $\mu_{0}$ given.

\subsection{A myopic-planner characterization}

Consider the problem of a social planner that maximizes (2.1) subject to equations (3.1)-(3.4) and the following employment feasibility condition at the establishment level:

$$
n_{t}\left(j, s_{j}^{t}, e\right) \leq(1-\delta) n_{t-1}\left(j, s_{j}^{t-1}, e\right)+a_{t-1}\left(j, s_{j}^{t-1}, e\right) \bar{m}_{t-1}, \text { for } j<t
$$

The planner takes the sequence $\left\{\bar{m}_{t}\right\}_{t=0}^{\infty}$ as given. Observe that equation (6.10) is identical to equation (3.5) except that that the arguments of $m$ are taken as given. Given that this social planner does not take into account how his decisions affect $m$, I will refer to him as a myopicplanner.

A solution to the myopic planner's problem can be described by a sequence $\left\{c_{t}, A_{t}, U_{t}, v_{t}, n_{t}\right.$, $\left.a_{t}, \theta_{t}, \mu_{t}\right\}_{t=0}^{\infty}$ that satisfies the following conditions.

The shadow value of a worker at an establishment of type $(x, s)$ must satisfy the following equation:

$$
\begin{aligned}
v_{t}(x, s)= & \max \left\{\theta_{t}, s_{t} F^{\prime}(x)+\delta \beta\left(\frac{c_{t}}{c_{t+1}}\right)^{\sigma} \theta_{t+1}\right. \\
& \left.+(1-\delta) \beta\left(\frac{c_{t}}{c_{t+1}}\right)^{\sigma} \sum_{s^{\prime}} v_{t+1}\left[(1-\delta) x+a_{t}(x, s) \bar{m}_{t}, s^{\prime}\right] Q\left(s, s^{\prime}\right)\right\}
\end{aligned}
$$

The optimal number of help-wanted ads created for an establishment of type $(x, s)$ is characterized by the following condition:

$$
\begin{aligned}
\beta\left(\frac{c_{t}}{c_{t+1}}\right)^{\sigma} \sum_{s^{\prime}} v_{t+1}\left[(1-\delta) n_{t}(x, s)+a_{t}(x, s) \bar{m}_{t}, s^{\prime}\right] Q\left(s, s^{\prime}\right) & \leq \frac{k}{\bar{m}_{t}}+\beta\left(\frac{c_{t}}{c_{t+1}}\right)^{\sigma} \theta_{t+1} \\
\text { with equality if } a_{t}(x, s) & >0 .
\end{aligned}
$$


The optimal employment rule $n_{t}(x, s)$ is characterized by a threshold level $\bar{x}_{t}(s)$ that satisfies the following condition:

$$
\begin{aligned}
\theta_{t}= & s_{t} F^{\prime}\left(\bar{x}_{t}(s)\right)+\delta \beta\left(\frac{c_{t}}{c_{t+1}}\right)^{\sigma} \theta_{t+1} \\
& +(1-\delta) \min \left[\beta\left(\frac{c_{t}}{c_{t+1}}\right)^{\sigma} \sum_{s^{\prime}} v_{t+1}\left[(1-\delta) \bar{x}_{t}(s)\right] Q\left(s, s^{\prime}\right), \frac{k}{\bar{m}_{t}}+\beta\left(\frac{c_{t}}{c_{t+1}}\right)^{\sigma} \theta_{t+1}\right] .
\end{aligned}
$$

The optimal employment rule is then given by

$$
n_{t}(x, s)=\min \left\{\bar{x}_{t}(s), x\right\}
$$

The optimal hiring opportunities creation rule $a_{t}(x, s)$ is characterized by a threshold level $\underline{x}_{t}(s)$ that satisfies the following condition:

$$
\beta\left(\frac{c_{t}}{c_{t+1}}\right)^{\sigma} \sum_{s^{\prime}} v_{t+1}\left[(1-\delta) \underline{x}_{t}(s), s^{\prime}\right] Q\left(s, s^{\prime}\right)=\frac{k}{\bar{m}_{t}}+\beta\left(\frac{c_{t}}{c_{t+1}}\right)^{\sigma} \theta_{t+1}
$$

The help-wanted ads creation rule is given by

$$
a_{t}(x, s) \bar{m}_{t}=\left\{\begin{array}{c}
0, \text { if } \min \left\{\bar{x}_{t}(s), x\right\}>\underline{x}_{t}(s) \\
(1-\delta)\left[\underline{x}_{t}(s)-\min \left\{\bar{x}_{t}(s), x\right\}\right], \text { otherwise }
\end{array}\right\} .
$$

The shadow value of an unemployed worker satisfies that

$$
\theta_{t}=c_{t}^{\sigma} \varphi+\beta\left(\frac{c_{t}}{c_{t+1}}\right)^{\sigma} \theta_{t+1}, \text { for } t \geq 0
$$

A myopically-efficient allocation with respect to $\left\{\bar{m}_{t}\right\}_{t=0}^{\infty}$ is a sequence $\left\{c_{t}, A_{t}, U_{t}, v_{t}, n_{t}, a_{t}, \theta_{t}, \mu_{t}\right\}_{t=0}^{\infty}$ such that equations (6.11)-(6.17) and (4.9)-(4.12) hold, with $\mu_{0}$ given.

In what follows, I provide a modified version of the Welfare Theorems, which I will refer to as the Myopic Welfare Theorems.

Proposition 6.1. (First Myopic Welfare Theorem) Let $\left\{c_{t}, b_{t}, A_{t}, U_{t}, J_{e t}, n_{t}, a_{t}, p_{t}^{w}, p_{t}^{a}, i_{t}, \mu_{t}\right\}_{t=0}^{\infty}$ be 
a competitive equilibrium with congestion externalities. Let

$$
\begin{aligned}
\bar{m}_{t} & =m\left(A_{t}, U_{t}\right) \\
\theta_{t} & =p_{t}^{w}, \\
v_{t} & =J_{e t}
\end{aligned}
$$

Then, $\left\{c_{t}, A_{t}, U_{t}, v_{t}, n_{t}, a_{t}, \theta_{t}, \mu_{t}\right\}_{t=0}^{\infty}$ is a myopically-efficient allocation with respect to $\left\{\bar{m}_{t}\right\}_{t=0}^{\infty}$.

Proposition 6.2. (Second Myopic Welfare Theorem) Let $\left\{c_{t}, A_{t}, U_{t}, v_{t}, n_{t}, a_{t}, \theta_{t}, \mu_{t}\right\}_{t=0}^{\infty}$ be a myopicallyefficient allocation with respect to $\left\{\bar{m}_{t}\right\}_{t=0}^{\infty}$. Suppose that

$$
\bar{m}_{t}=m\left(A_{t}, U_{t}\right) \text {, for every } t \text {. }
$$

Let

$$
\begin{aligned}
p_{t}^{w} & =\theta_{t} \\
J_{e t} & =v_{t} \\
p_{t}^{a} & =k \\
b_{t} & =0 \\
\frac{1}{1+i_{t}} & =\beta\left(\frac{c_{t}}{c_{t+1}}\right)^{\sigma}
\end{aligned}
$$

Then, $\left\{c_{t}, b_{t}, A_{t}, U_{t}, J_{e t}, n_{t}, a_{t}, p_{t}^{w}, p_{t}^{a}, i_{t}, \mu_{t}\right\}_{t=0}^{\infty}$ is a competitive equilibrium with congestion externalities

The characterization of a competitive equilibrium with congestion externalities as a myopicefficient allocation will turn out to be extremely useful in computations.

\section{The optimal policy regime}

In this section I introduce government policies to the competitive equilibrium with congestion externalities of the previous section. In particular, I introduce a tax $\tau_{t}$ to help-wanted ads and a subsidy $\rho_{t}$ to unemployed workers. Any negative (positive) difference between the tax revenues and the subsidy payments associated with those tax rates are rebated (taxed) to households in a lump-sum way. The purpose is to look for government interventions that will attain the first best 
allocation described in Section 4.

The date $t$ problem of an establishment that has $e$ workers carried over from the previous period, $m$ hiring opportunities and current productivity level $s$ is now given by

$$
\begin{aligned}
J_{t}(e, m, s)= & \max _{n_{t}, h_{t}, f_{t}, a_{t}}\left\{s F\left(n_{t}\right)+p_{t}^{w}\left(f_{t}-h_{t}\right)-\left(1+\tau_{t}\right) p_{t}^{a} a_{t}\right. \\
& \left.+\frac{1}{1+i_{t}} \sum_{s^{\prime}} J_{t+1}\left[(1-\delta) n_{t}, m_{t+1}, s^{\prime}\right] Q\left(s, s^{\prime}\right)+\frac{1}{1+i_{t}} p_{t+1}^{w} \delta n_{t}\right\}
\end{aligned}
$$

subject to

$$
\begin{aligned}
n_{t} & =e+h_{t}-f_{t} \\
h_{t} & \leq m \\
m_{t+1} & =a_{t} m\left(A_{t}, U_{t}\right)
\end{aligned}
$$

where the purchases of help-wanted ads are now taxed at the rate $\tau_{t}$.

The first order conditions for the establishment's problem are the following:

$$
\begin{aligned}
J_{e t}(x, s)= & \max \left\{p_{t}^{w}, s F^{\prime}(x)+\frac{1}{1+i_{t}} p_{t+1}^{w} \delta\right. \\
& \left.+(1-\delta) \frac{1}{1+i_{t}} \sum_{s^{\prime}} J_{e, t+1}\left[(1-\delta) x+a_{t}(x, s) m\left(A_{t}, U_{t}\right), s^{\prime}\right] Q\left(s, s^{\prime}\right)\right\}
\end{aligned}
$$

and

$$
\begin{aligned}
\frac{1}{1+i_{t}} \sum_{s^{\prime}} J_{e, t+1}\left[(1-\delta) n_{t}(x, s)+a_{t}(x, s) m\left(A_{t}, U_{t}\right), s^{\prime}\right] Q\left(s, s^{\prime}\right) & \leq \frac{\left(1+\tau_{t}\right) p_{t}^{a}}{m\left(A_{t}, U_{t}\right)}+\frac{1}{1+i_{t}} p_{t+1}^{w} \\
\text { with equality if } a_{t}(x, s) & >0
\end{aligned}
$$

The establishment's employment rule $n_{t}(x, s)$ has the same form as in the previous sections. It is characterized by a threshold level $\bar{x}_{t}(s)$ that satisfies the following condition:

$$
\begin{aligned}
p_{t}^{w}= & s F^{\prime}\left(\bar{x}_{t}(s)\right)+\frac{1}{1+i_{t}} p_{t+1}^{w} \delta \\
& +(1-\delta) \min \left[\frac{1}{1+i_{t}} \sum_{s^{\prime}} J_{e, t+1}\left[(1-\delta) \bar{x}_{t}(s), s^{\prime}\right] Q\left(s, s^{\prime}\right), \frac{\left(1+\tau_{t}\right) p_{t}^{a}}{m\left(A_{t}, U_{t}\right)}+\frac{1}{1+i_{t}} p_{t+1}^{w}\right]
\end{aligned}
$$


The optimal employment rule is then given by

$$
n_{t}(x, s)=\min \left\{\bar{x}_{t}(s), x\right\}
$$

The optimal hiring opportunities creation rule also has the same form as before. It is characterized by a threshold level $\underline{x}_{t}(s)$ that satisfies the following condition:

$$
\frac{1}{1+i_{t}} \sum_{s^{\prime}} J_{e, t+1}\left[(1-\delta) \underline{x}_{t}(s), s^{\prime}\right] Q\left(s, s^{\prime}\right)=\frac{\left(1+\tau_{t}\right) p_{t}^{a}}{m\left(A_{t}, U_{t}\right)}+\frac{1}{1+i_{t}} p_{t+1}^{w}
$$

The help-wanted ads creation rule is given by

$$
a_{t}(x, s) m\left(A_{t}, U_{t}\right)=\left\{\begin{array}{c}
0, \text { if } \min \left\{\bar{x}_{t}(s), x\right\}>\underline{x}_{t}(s) \\
(1-\delta)\left[\underline{x}_{t}(s)-\min \left\{\bar{x}_{t}(s), x\right\}\right], \text { otherwise }
\end{array}\right\} .
$$

The representative job-posting company solves the following static profit maximization problem:

$$
\max \left\{p_{t}^{a} A_{t}-k A_{t}\right\}
$$

where $p_{t}^{a}$ is the price of a help-wanted ad, $k$ is the cost of producing a help-wanted ad, and $A_{t}$ are the total help-wanted ads produced. Thus, at equilibrium we must have that

$$
p_{t}^{a}=k
$$

The date $t$ problem of a household that had $u_{t-1}$ unemployed members during the previous period and that during the current period has $j_{t}$ job opportunities and $b_{t}$ bond holdings is given by

$$
H_{t}\left(u_{t-1}, j_{t}, b_{t}\right)=\max \left\{\frac{c_{t}^{1-\sigma}-1}{1-\sigma}+\varphi u_{t}+\beta H_{t+1}\left(u_{t}, j_{t+1}, b_{t+1}\right)\right\}
$$


subject to

$$
\begin{aligned}
c_{t}+b_{t+1} & \leq \rho_{t} u_{t}+p_{t}^{w}\left(h_{t}-f_{t}\right)+\left(1+i_{t-1}\right) b_{t}+\Pi_{t}+T_{t} \\
u_{t} & =\left(u_{t-1}-j_{t}\right)+f_{t}+\left(j_{t}-h_{t}\right), \\
h_{t} & \leq j_{t} \\
f_{t} & \leq 1-u_{t-1}, \\
j_{t+1} & =u_{t} \frac{M_{t+1}}{U_{t}}
\end{aligned}
$$

where unemployed workers are now subsidized at the rate $\rho_{t}$ and the household now faces a lumpsum tax $T_{t}$. Since the second and third constraints must hold with strict inequality at equilibrium, the price of a worker must satisfy the following condition:

$$
p_{t}^{w}=c_{t}^{\sigma} \varphi+\rho_{t}+\beta\left(\frac{c_{t}}{c_{t+1}}\right)^{\sigma} p_{t+1}^{w}
$$

Also observe that the solution to the household's problem requires that

$$
\frac{1}{1+i_{t}}=\beta\left(\frac{c_{t}}{c_{t+1}}\right)^{\sigma}
$$

The government balances its budget period-by-period. This means that the lump-sum taxes $T_{t}$ must be given by

$$
T_{t}=\rho_{t} U_{t}-\tau_{t} p_{t}^{a} A_{t}
$$

A competitive equilibrium with externalities and policy intervention is a sequence $\left\{c_{t}, b_{t}, A_{t}, U_{t}\right.$, $\left.J_{e t}, n_{t}, a_{t}, p_{t}^{w}, p_{t}^{a}, i_{t}, \mu_{t}, \tau_{t}, \rho_{t}, T_{t}\right\}_{t=0}^{\infty}$ such that $b_{t}=0$ and equations (7.1)-(7.10) and (4.9)-(4.12) are satisfied every period $t$, with $\mu_{0}$ given.

The following proposition characterizes the optimal policy intervention, i.e., the policy regime that attains the first best allocation.

Proposition 7.1. (Necessity of optimal policy regime) Let $\left\{c_{t}, A_{t}, U_{t}, v_{t}, n_{t}, a_{t}, \theta_{t}, \gamma_{t}, \mu_{t}\right\}_{t=0}^{\infty}$ be the 
unique efficient allocation (as defined in Section 4). Define,

$$
\begin{aligned}
\tau_{t} & =-\frac{A_{t} m_{A}\left(A_{t}, U_{t}\right)}{m\left(A_{t}, U_{t}\right)+A_{t} m_{A}\left(A_{t}, U_{t}\right)}, \\
\rho_{t} & =\frac{k A_{t} m_{U}\left(A_{t}, U_{t}\right)}{m\left(A_{t}, U_{t}\right)+A_{t} m_{A}\left(A_{t}, U_{t}\right)}, \\
T_{t} & =0 \\
p_{t}^{w} & =\theta_{t} \\
p_{t}^{a} & =k \\
J_{e t} & =v \\
b_{t} & =0 \\
\frac{1}{1+i_{t}} & =\beta\left(\frac{c_{t}}{c_{t+1}}\right)^{\sigma}
\end{aligned}
$$

Then, $\left\{c_{t}, b_{t}, A_{t}, U_{t}, J_{e t}, n_{t}, a_{t}, p_{t}^{w}, p_{t}^{a}, i_{t}, \mu_{t}, \tau_{t}, \rho_{t}, T_{t}\right\}_{t=0}^{\infty}$ is a competitive equilibrium with externalities and policy intervention.

The converse is also true.

Proposition 7.2. (Sufficiency of optimal policy regime) Let $\left\{c_{t}, b_{t}, A_{t}, U_{t}, J_{e t}, n_{t}, a_{t}, p_{t}^{w}, p_{t}^{a}, i_{t}\right.$, $\left.\mu_{t}, \tau_{t}, \rho_{t}, T_{t}\right\}_{t=0}^{\infty}$ be a competitive equilibrium with externalities and policy intervention such that

$$
\begin{aligned}
\tau_{t} & =-\frac{A_{t} m_{A}\left(A_{t}, U_{t}\right)}{m\left(A_{t}, U_{t}\right)+A_{t} m_{A}\left(A_{t}, U_{t}\right)}, \\
\rho_{t} & =\frac{k A_{t} m_{U}\left(A_{t}, U_{t}\right)}{m\left(A_{t}, U_{t}\right)+A_{t} m_{A}\left(A_{t}, U_{t}\right)}, \\
T_{t} & =0
\end{aligned}
$$

Let

$$
\begin{aligned}
\theta_{t} & =p_{t}^{w} \\
\gamma_{t} & =\frac{k}{m\left(A_{t}, U_{t}\right)+A_{t} m_{A}\left(A_{t}, U_{t}\right)} \\
v_{t} & =J_{e t}
\end{aligned}
$$

Then, $\left\{c_{t}, A_{t}, U_{t}, v_{t}, n_{t}, a_{t}, \theta_{t}, \gamma_{t}, \mu_{t}\right\}_{t=0}^{\infty}$ is the unique efficient allocation

Observe that the optimal policy regime is fully funded: It does not require lump-sum taxes or subsidies to implement it. It is also straightforward to verify that when the matching function has 
the following Cobb-Douglas functional form

$$
M_{t}=\Omega U_{t}^{\phi} A_{t}^{1-\phi}
$$

the optimal policy simplifies to:

$$
\begin{aligned}
\tau_{t} & =\frac{\phi}{1-\phi}, \\
\rho_{t} & =k \frac{\phi}{1-\phi} \frac{A_{t}}{U_{t}} .
\end{aligned}
$$

That is, while the optimal tax rate on help-wanted ads is constant, the unemployment subsidy varies directly with the degree of market tightness.

This characterization of the optimal policy in the Cobb-Douglas case is closely related to Hosios' efficiency condition in the context of bilateral Nash bargaining (Hosios [7]). To see this, observe that $J_{e t}-p_{t}^{w}$ can be interpreted as the surplus associated with the marginal worker. Hosios' condition states that the employer must receive a fraction $1-\phi$ of this surplus in order to achieve efficiency. Since in a Walrasian equilibrium the employer receives all of this surplus, a fraction $\phi$ must be taxed away and be given to the workers in the form of an unemployment subsidy, effectively mimicking a higher Nash bargaining weight for the workers. An inspection of equations (7.2) and (7.13) indicates that this exactly what the optimal policy achieves.

\section{Calibration}

Given that the preponderant view in the literature is that the matching process is subject to congestion externalities, in this section I calibrate the steady state of the competitive equilibrium with externalities and no policy interventions described in Section 6 to long-run U.S. observations. ${ }^{4}$ The following section will explore the business cycle properties of this economy as well as the effects of introducing the optimal policy regime.

I choose the model time period to be two-weeks to accommodate for the relatively short average durations of unemployment and vacancies in the U.S. economy. Calibrating to an annual interest rate of 4 percent, which is a standard value in the macro literature, then requires a time discount factor $\beta$ equal to 0.99835 .

\footnotetext{
${ }^{4} \mathrm{~A}$ future version of the paper will also consider an efficient competitive equilibrium scenario.
} 
The preference parameter $\sigma$, which determines the elasticity of intertemporal substitution, is taken as a free parameter. However, I will restrict attention to two values: $\sigma=0$ and $\sigma=1$. The first value is often used in the search literature based on the Mortensen and Pissarides [9] model (e.g. Hall [5], Hagedorn and Manovskii [4] and Shimer [11]). The second value, which is consistent with the stylized growth facts, is generally used in the macro literature. In what follows, I describe the calibration strategy assuming that $\sigma=0$. At the end of the section, I discuss how to accommodate the other case.

It is straightforward to verify that doubling the utility of leisure $\varphi$, the values of all idiosyncratic productivity levels $z$, and the cost of creating a help-wanted ad $k$ doubles the units in which consumption and output are measured but leaves all other equilibrium variables unchanged. As a consequence, I normalize the utility of leisure $\varphi$ to one.

I assume that the production function has the following functional form:

$$
y_{t}=s_{t} n_{t}^{\alpha}
$$

where $0<\alpha<1$. Following the macro literature I choose the curvature parameter $\alpha$ to reproduce a labor share in National Income $(1-\beta) p^{w} N / Y$ equal to 0.64 .

The values for the idiosyncratic productivity levels $s$, the distribution over initial productivity levels $\psi$ and the transition matrix $Q$ are key determinants of the job-flows generated by the model. As a consequence I choose them to reproduce observations from the Business Employment Dynamics (BED) data set, which is a virtual census of establishments level dynamics. Since BED data across establishment sizes can be found for the nine employment ranges shown in the first column of Table 1, I restrict the idiosyncratic productivity levels $s$ to take nine positive values and choose them so that all establishments with a same idiosyncratic productivity level choose employment levels in the same range.

The average size of new entrants can be obtained by dividing the total gross job gains at opening establishments by the total number of opening establishments. Using data between 1992:Q3 and 2005:Q4, I find that the average size of new entrants is equal to 5.3 employees. Since this is a small number, I restrict the distribution over initial productivity levels $\psi$ to put positive mass on only the two lowest values of $s$ and choose $\psi\left(s_{1}\right)$ to reproduce that average size.

Similarly, the average size at exit can be obtained by dividing the total gross job losses at closing establishments by the total number of closing establishments. Using data for the same time period 
as above, I find that the average size at exit is equal to 5.2 employees. Since this is also a small number, I restrict the probabilities of transiting to a zero productivity level $Q(s, 0)$ to take positive values only at the two lowest values of $s$ and choose $Q\left(s_{1}, 0\right) / Q\left(s_{2}, 0\right)$ to reproduce that average size. The level for $Q\left(s_{1}, 0\right)$ is then chosen to reproduce the average quarterly rate of gross job losses due to closing establishments (JLD) over the same time period, which is equal to $1.6 \% .^{5}$

The rest of the transition matrix $Q$ is parameterized with enough flexibility to reproduce important establishment level observations. The only restriction that I impose is that $Q\left(s_{i}, s_{j}\right)>0$ only if $j=i-1, j=i$ or $j=i+1$. Since the rows of $Q$ add to one this introduces 16 parameters (2 parameters each, for $i=2, \ldots, 8$, and 1 parameter each, for $i=1,9)$. Eight of these parameters are chosen to reproduce the shares in total employment across size classes (which provide eight independent observations). The other eight parameters are chosen to reproduce the shares in total gross job gains across size classes (which also provide eight independent observations). I must point out that the BED does not tabulate statistics across size classes in its regular reports. However, these statistics can be found in Okolie [10] (Tables 1 and 3) for the first two quarters of 2000. These statistics together with the corresponding model statistics are shown in the first panel of Table 1. The second panel reports the average sizes at entry and exit both in the model and the data. We see that the model does a good job at reproducing these observations. As a test of the model, Table 1 also includes the shares in total gross job losses across size classes for the first two quarters of 2000 in Okolie [10], and the average quarterly rates of gross job gains due to expanding establishments (JGE), gross job gains due to opening establishments (JGB), gross job losses due to contracting establishments (JLC), and exit rates reported by the BED for the period 1992:Q32005:Q4. Although the fit is not perfect, we see that the model also does a good job at reproducing these statistics. ${ }^{6}$

The exogenous separation rate $\delta$ and the number of establishments created every period $\varsigma$ are important determinants of the worker flows in and out of unemployment, so I calibrate them to reproduce this type of observations. In particular, I target an average monthly separation rate from employment equal to $3.5 \%$ and an average monthly hazard rate from unemployment equal to $46 \%$,

\footnotetext{
${ }^{5}$ Since the model is bi-weekly, monthly and quarterly statistics are constructed following establishments over two and six consecutive time periods, respectively.

${ }^{6}$ The main discrepancy is with the shares in total gros job losses for the size ranges $(5,10)$ and $(10,20)$, which are too large in the first case and too small in the second. This could be remedied by allowing for a postivive $Q\left(s_{3}, 0\right)$ and by lowering $Q\left(s_{2}, 0\right)$, since the range $(5,10)$ accounts for a large fraction of the establishments closings. However, I do not expect that such modification would affect the main results in the paper.
} 
which were estimated by Shimer [12] using CPS data between 1948 and 2004. Since the separation rate of $3.5 \%$ is significantly larger than the rate of job losses experienced by establishments, I select a positive value of $\delta$ to reproduce the excess worker reallocation. ${ }^{7}$ Also, observe that the separation and hazard rates estimated by Shimer [12] imply a steady state unemployment rate equal to $7.1 \%$. The average size of establishments implied by the shares in total employment in Table 1 thus determine the entry rate of establishments $\varsigma$ needed to generate an aggregate employment level $N$ equal to 0.929 .

I assume that the matching function takes the Cobb-Douglas form in equation (7.12). The matching parameters $\Omega$ and $\phi$ together with the cost of posting a help-wanted ad $k$ are important determinants of the role that vacancies play in the model economy. In fact, one of these parameters entails a mere normalization: It is easy to show that dividing $k$ by a factor $\lambda$, and dividing $\Omega$ by a factor $\lambda^{1-\phi}$ leaves the equilibrium unchanged except that the units in which vacancies $A$ are measured are multiplied by the factor $\lambda$. Given this result, I normalize $\Omega$ so that the units in which vacancies are measured are such that the vacancy rate $A /(A+N)$ of continuing establishments equals $2.2 \%$, which is the the average between 2000 and 2005 in the JOLTS dataset. ${ }^{8}$ This normalization allows me to identify $k$ with the cost of creating a vacancy. Since Hagedorn and Manovskii [4] estimate that the flow cost of posting a vacancy is $60 \%$ of the wage rate and since the wage rate in my model economy is $\varphi=1$, I calibrate $k$ to 0.60 . In turn, I calibrate the curvature parameter $\phi$ in the matching function (7.12) to 0.72 which is the elasticity estimated by Shimer [11].

As a test of the model Table 2 reports a set of basic monthly statistics both for JOLTS and the model economy that were not used as calibration targets. ${ }^{9}$ We see that the model does a reasonable job at reproducing the hiring and separation rates for continuing establishments, the vacancy yield rate (i.e. the hires per vacancy), the fraction of vacancies with zero hirings and the fraction of hires with zero vacancies. Time aggregation plays an important role in generating a vacancy yield rate greater than one and the large fraction of hires with zero vacancies since, following JOLTS, vacancies are measured at the end of a period and hirings are measured over the two subsequent periods. The low rate of exogenous separations $\delta$ explains the model's success in reproducing the

\footnotetext{
${ }^{7}$ Not surprisingly, my calibrated value of $\delta$ is smaller than the quit rate of workers measured by JOLTS, since many of those separations entail job-to-job transitions that the model abstracts from.

${ }^{8}$ I restrict attention to continuing establishments because this is the only type of establishments included in JOLTS.

${ }^{9}$ JOLTS statistics are from Davis et al. [?, ?].
} 
fraction of vacancies with zero hirings. The reason is that a significant number of establishments reach the lower thresholds $\underline{x}(s)$ and start hiring just enough workers to replenish the exogenous separation of workers. Since the monthly rate of exogenous separation is less than $1 \%$, following Davis et al. [?, ?], I classify these establishments (and their corresponding vacancies) as having zero hirings. Observe that the model performs less satisfactorily in reproducing the fraction of establishments with zero vacancies and the fraction of establishments with zero hiring. The small

number of idiosyncratic productivity levels that I allow for explains this result since they lead to a large number of inactive establishments. Introducing more idiosyncratic productivity level would generate smaller and more frequent adjustments and improve the performance of the model in this dimension. However, I do not expect that this modification to change the main results in the paper.

Table 3 displays all calibrated parameter values for the case of linear preferences, i.e. for the case $\sigma=0$. The other case is easily handled since at steady state the curvature parameter $\sigma$ only enters equation 6.8. In particular, when $\sigma$ is greater than zero I leave all parameter values unchanged except for the utility of leisure $\varphi(\sigma)$ which I set to

$$
\phi(\sigma)=\varphi(0) c(0)^{-\sigma}
$$

where $c(0)$ and $\varphi(0)$ are the steady state consumption level and the utility of leisure in the case $\sigma=0$. This choice of $\varphi(\sigma)$ leaves the calibrated steady state allocation unchanged across the different values of $\sigma$. The values that satisfy equation (8.1) turn out to be $\varphi(1)=0.6846$ when $\sigma$ is equal to one.

\section{Results}

Before analyzing the effects of introducing the optimal policy regime to the calibrated economy of the previous section, I evaluate the empirical plausibility of that economy by contrasting its business cycle fluctuations with those of the U.S. I do this by introducing an aggregate productivity shock common to all establishments. In particular, I modify the production function of establishments to the following:

$$
y_{t}=e^{z_{t}} s_{t} n_{t}^{\alpha},
$$

where $z_{t}$ is an aggregate productivity shock that evolves according to a standard $\mathrm{AR}(1)$ process

$$
z_{t+1}=\rho_{z} z_{t}+\varepsilon_{t+1}
$$


and $\varepsilon_{t+1}$ is an i.i.d. normally distributed innovation, with zero mean and standard deviation $\sigma_{\varepsilon}$. I choose $\rho_{z}$ and $\sigma_{\varepsilon}$ to reproduce the empirical behavior of Solow residuals in the U.S. economy measured at quarterly frequencies. Using GDP and civilian employment data between 1951:1 and 2004:4 I find that the logarithm of these residuals are highly persistent and that their changes have a standard deviations of $0.008 .^{10}$ It turns out that values of $\rho_{z}=0.96$ and $\sigma_{\varepsilon}=0.0044$ are needed to reproduce this type of behavior for the Solow residuals measured from the artificial data generated by the model economy.

The first panel of Table 4 reports business cycle statistics between 1951:1 and 2004:4 for GDP $(\mathrm{Y})$, civilian employment $(\mathrm{N})$, civilian unemployment $(\mathrm{U})$, the help-wanted ads index $(\mathrm{A})$, market tightness $(\mathrm{A} / \mathrm{U})$ and average labor productivity $(\mathrm{Y} / \mathrm{N})$. Before any statistics were computed all the time series were logged and detrended using a Hoddrik-Prescott filter with smothing parameter 1,600. The statistics are the vector of standard deviations and the correlation matrix. We see that employment and average productivity fluctuate $0.60 \%$ as much as output, while unemployment and help-wanted ads fluctuate about 8 times as much. Market tightness is even more variable: it fluctuates 16 times as much as output. All variables are strongly procyclical except for unemployment, which is strongly contercyclical. We also see that the data displays a clear Beveridge curve: Unemployment and help-wanted ads are strongly negatively correlated. The correlation of unemployment with market tightness is also close to -1 while the correlation with average productivity is much weaker: only -0.46 .

The second panel of Table 4 describes analogous statistics from the model economy with linear preferences. ${ }^{11}$ We see that the model generates only a slightly smaller standard deviation of output than the data and that the standard deviations of all variables relative to output have the correct magnitude. The correlations of all variables with output have the correct sign but they are a bit too strongly correlated. We also see that the model generates the Beveridge curve, although the correlation between unemployment and help-wanteed ads is a bit weaker than in the data. The corelation of unemployment with market tightness is as strong as in the U.S. economy while its correlation with average productivity is a touch weaker. Overall, we see that the model reproduces U.S. business cycle statistics surprisingly well.

\footnotetext{
${ }^{10}$ Solow residuals were constructed using a labor share of $64 \%$.

${ }^{11}$ The model with $\log$ preferences generates virtually no employment fluctuations. Actually, if the cost of creating help-wanted ads was $e^{z t} k$, i.e. if it was perfectly correlated with the aggregate productivity shock, the economy with $\log$ preferences would generate zero employment fluctuations.
} 
Having established the empirical relevance of the equilibrium with externalities, I now turn to measure the consequences of the congestion effects. In particular, I evaluate the effects of introducing the optimal policy characterized by Propositions 7.1 and 7.2. It turns out that the optimal policy is given by a tax of $257 \%$ on the creation of help-wanted ads and an unemployment subsidy equal to $4.4 \%$ of the wage rate (i.e. of the user cost of labor $(1-\beta) p^{w}$ ). Table 5 reports the steady-state results. We see that the optimal policy is extremely contractionary: output decreases by $6.2 \%$, consumption by $5.5 \%$, employment by $9.9 \%$, and vacancies by $91.7 \%$. Matches increase by $13.4 \%$ despite the decrease in vacancies because of a sharp increase in unemployment. In fact, the unemployment rate increases from $7.2 \%$ in the steady state with congestion externalities to $16.4 \%$ under the optimal policy regime. Observe that the higher number of matches allow for higher rates of job gains due to expanding establishments and job losses due to contracting establishments, leading to a better distribution of workers across establishments. Also observe that the drop in consumption is more than compensated by the large increase in leisure, and the optimal policy leads to large welfare gains: Agents in the steady-state of the equilibrium with congestion externalities would require a $0.8 \%$ permanent increase in consumption in order to be indifferent with living in the efficient steady-state.

Figure 1 shows the transitionary dynamics generated by the optimal policy over the first year of the reform. There are two important features to observe. First, the transitionary dynamics are rather slow: Only by the end of the year variables appear to be settling at their stationary values. Second, unemployment jumps and help-wanted ads plummet immediately after the reform. While output drops with the initial increase in unemployment, consumption is not very much affected on impact because of the large savings in help-wanted ads. Since consumption does not initially change and agents start enjoying a significant amount of leisure right away, there are large welfare gains early on in the reform. This, coupled with the long transitionary dynamics, imply that the welfare gains of the reform can be much higher once the transitionary dynamics are considered. Table 6 shows that this is indeed the case: The welfare gains of the reform increase from $0.8 \%$ to $1.1 \%$ when the short-run effects are taken into account..

Finally, Table 7 shows how the introduction of the optimal policy affects the business cycle fluctuations of the economy. The first panel reproduces the business cycle statistics for the equilibrium with congestion externalities. The second panel describes analogous statistics for the efficient equilibrium. We see that the optimal policy dampens the response of the economy to aggregate producitivity shocks quite substantially. In particular, the standard deviation of output decreases 
by $3 \%$ and the standard deviation of employment decreases by $17 \%$. However, the largest effects are in the volatility of unemployment, which plummets by $70 \%$. Despite of this, the correlation matrices indicate that the comovements between the different variables are not significantly affected. In particular, the correlation between unemployment and help-wanted ads only changes from -0.75 to -0.67 , i.e. there are little effects on the slope of the Beveridge curve. 


\section{References}

[1] Alvarez, F. and M. Veracierto, M. 2006. Fixed-Term Employment Contracts in an Equilibrium Search Model. NBER Working Paper.

[2] Bentolila, S. and G. Bertola. 1990. Firing Costs and Labor Demand: How Bad is Eurosclerosis? Review of Economic Studies, 57, 381-402.

[3] Davis, D., Faberman J. and J. Haltiwanger. 2006. The Flow Approach to Labor Markets: New Data Sources and Micro-Macro Links. Journal of Economic Perspectives, Summer, 3-26.

[4] Hagedorn M. and I. Manovskii. 2006. The Cyclical Behavior of Equilibrium Unemployment and Vacancies Revisited. Mimeo.

[5] Hall R. 2005. Employment Fluctuations with Equilibrium Wage Stickiness. American Economic Review, 95(1), 50-65.

[6] Hopenhayn, H. and R. Rogerson. 1993. Job Turnover and Policy Evaluation: A General Equilibrium Analysis. Journal of Political Economy, 101, 915-38.

[7] Hosios, A. 1990. On the Efficiency of Matching and Related Models of Search and Unemployment. Review of Economic Studies, 57, 279-98.

[8] Lucas, R. and E. C. Prescott. 1974. Equilibrium Search and Unemployment. Journal of Economic Theory, 7, 188-209.

[9] Mortensen, D. and C. Pissarides. 1994. Job Creation and Job Destruction in the Theory of Unemployment. Review of Economic Studies, 61, 397-415.

[10] Okolie, C. 2004. Why size class class methodology matters in analyses of net and gross job flows. Monthly Labor Review, July, xx-xx.

[11] Shimer, R. 2005. The Cyclical Behavior of Equilibrium Unemployment and Vacancies. American Economic Review, 95(1), 25-49.

[12] Shimer, R. 2005. Reassessing the Ins and Outs of Unemployment. University of Chicago, mimeo. 


\section{Table 1}

Quarterly observations

\begin{tabular}{|c|c|c|c|c|c|c|}
\hline \multicolumn{7}{|c|}{ Panel A: BED data, March 2000 to June 2000} \\
\hline \multirow{2}{*}{$\begin{array}{c}\text { Size } \\
\text { Classes* } \\
\text { (employees) }\end{array}$} & \multicolumn{3}{|c|}{ Data } & \multicolumn{3}{|c|}{ Model } \\
\hline & $\begin{array}{c}\text { Shares in } \\
\text { Employment }\end{array}$ & $\begin{array}{l}\text { Shares in } \\
\text { Job Gains }\end{array}$ & $\begin{array}{l}\text { Shares in } \\
\text { Job Losses }\end{array}$ & $\begin{array}{c}\text { Shares in } \\
\text { Employment }\end{array}$ & $\begin{array}{l}\text { Shares in } \\
\text { Job Gains }\end{array}$ & $\begin{array}{l}\text { Shares in } \\
\text { Job Losses }\end{array}$ \\
\hline$[1,5)$ & $6.4 \%$ & $16.9 \%$ & $9.7 \%$ & $7.6 \%$ & $15.0 \%$ & $7.5 \%$ \\
\hline$[5,10)$ & $8.1 \%$ & $13.1 \%$ & $11.6 \%$ & $6.6 \%$ & $15.7 \%$ & $20.5 \%$ \\
\hline$[10,20)$ & $10.7 \%$ & $14.9 \%$ & $13.7 \%$ & $11.0 \%$ & $16.3 \%$ & $4.2 \%$ \\
\hline$[20,50)$ & $16.6 \%$ & $18.3 \%$ & $18.2 \%$ & $17.1 \%$ & $17.1 \%$ & $16.9 \%$ \\
\hline$[50,100)$ & $13.1 \%$ & $11.6 \%$ & $12.6 \%$ & $12.5 \%$ & $11.7 \%$ & $14.4 \%$ \\
\hline$[100,250)$ & $16.5 \%$ & $11.9 \%$ & $14.6 \%$ & $16.8 \%$ & $12.5 \%$ & $13.6 \%$ \\
\hline$[250,500)$ & $9.8 \%$ & $5.9 \%$ & $8.5 \%$ & $9.5 \%$ & $5.0 \%$ & $11.5 \%$ \\
\hline$[500,1000)$ & $7.3 \%$ & $3.5 \%$ & $5.4 \%$ & $7.5 \%$ & $6.9 \%$ & $5.6 \%$ \\
\hline$[1000, \infty)$ & $11.6 \%$ & $4.2 \%$ & $5.9 \%$ & $11.3 \%$ & $0.0 \%$ & $5.9 \%$ \\
\hline \multicolumn{7}{|c|}{ Panel B: BED data, 1992:Q3 to 2005:Q4 } \\
\hline & \multicolumn{3}{|c|}{ Data } & \multicolumn{3}{|c|}{ Model } \\
\hline size at entry & \multicolumn{3}{|c|}{5.3} & \multicolumn{3}{|c|}{4.7} \\
\hline size at exit & \multicolumn{3}{|c|}{5.2} & \multicolumn{3}{|c|}{4.8} \\
\hline JGB & \multicolumn{3}{|c|}{$1.7 \%$} & \multicolumn{3}{|c|}{$1.6 \%$} \\
\hline JGE & \multicolumn{3}{|c|}{$6.2 \%$} & \multicolumn{3}{|c|}{$6.2 \%$} \\
\hline JLD & \multicolumn{3}{|c|}{$1.6 \%$} & \multicolumn{3}{|c|}{$1.6 \%$} \\
\hline JLC & \multicolumn{3}{|c|}{$6.0 \%$} & \multicolumn{3}{|c|}{$6.2 \%$} \\
\hline Exit Rate & \multicolumn{3}{|c|}{$5.2 \%$} & \multicolumn{3}{|c|}{$6.9 \%$} \\
\hline
\end{tabular}

$(*)$ : The classification of establishments into size classes is as follows: Continuing establishments between $t$ and $t+1$ are classified according to their size at $t$, opening establishments at $t+1$ are classified according to their size at $t+1$, closing establishments at $t+1$ are classified according to their size at $t$. 


\section{Table 2}

Monthly observations

\begin{tabular}{|c|c|c|}
\hline \multicolumn{3}{|c|}{ Panel A: CPS data, 1948-2004 } \\
\hline & Data & Model \\
\hline Separation rate & $3.5 \%$ & $3.6 \%$ \\
\hline Hazard rate & $46 \%$ & $46 \%$ \\
\hline \multicolumn{3}{|c|}{ Panel B: JOLTS data, 2000-2005 } \\
\hline & Data & Model \\
\hline Vacancy rate & $2.2 \%$ & $2.2 \%$ \\
\hline Hiring rate & $3.2 \%$ & $3.0 \%$ \\
\hline Separation rate & $3.1 \%$ & $3.0 \%$ \\
\hline Vacancies yield rate & 1.3 & 1.3 \\
\hline$\%$ Vacancies with zero hiring & $18.7 \%$ & $19.0 \%$ \\
\hline$\%$ Hiring with zero vacancies & $42.3 \%$ & $58.1 \%$ \\
\hline$\%$ Establishments with zero hiring & $81.6 \%$ & $90.0 \%$ \\
\hline$\%$ Establishments with zero vacancies & $87.6 \%$ & $95.0 \%$ \\
\hline
\end{tabular}




\section{Table 3}

Parameter values $(\sigma=0)$

\begin{tabular}{|c|c|c|c|c|c|c|c|c|c|c|}
\hline \multicolumn{11}{|c|}{ General Parameters: } \\
\hline & $\beta$ & $\varphi$ & $\alpha$ & $\delta$ & $\varsigma$ & $k$ & $\Omega$ & \multicolumn{3}{|l|}{$\phi$} \\
\hline & 0.9984 & 1.0 & 0.64 & 0.0045 & 0.0006 & 0.61 & 1.493 & \multicolumn{3}{|l|}{0.219} \\
\hline \multicolumn{11}{|c|}{ Productivity levels: } \\
\hline & $s_{0}$ & $s_{1}$ & $s_{2}$ & $s_{3}$ & $s_{4}$ & $s_{5}$ & $s_{6}$ & $s_{7}$ & $s_{8}$ & $s_{9}$ \\
\hline & 0.0 & 2.19 & 3.33 & 4.0 & 5.71 & 7.16 & 10.24 & 13.33 & 16.38 & 20.0 \\
\hline \multicolumn{11}{|c|}{ Distribution over initial productivity levels: } \\
\hline & $\psi\left(s_{0}\right)$ & $\psi\left(s_{1}\right)$ & $\psi\left(s_{2}\right)$ & $\psi\left(s_{3}\right)$ & $\psi\left(s_{4}\right)$ & $\psi\left(s_{5}\right)$ & $\psi\left(s_{6}\right)$ & $\psi\left(s_{7}\right)$ & $\psi\left(s_{8}\right)$ & $\psi\left(s_{9}\right)$ \\
\hline & 0.0 & 0.017 & 0.983 & 0.0 & 0.0 & 0.0 & 0.0 & 0.0 & 0.0 & 0.0 \\
\hline \multicolumn{11}{|c|}{ Transition matrix $Q$ : } \\
\hline & $s_{0}^{\prime}$ & $s_{1}^{\prime}$ & $s_{2}^{\prime}$ & $s_{3}^{\prime}$ & $s_{4}^{\prime}$ & $s_{5}^{\prime}$ & $s_{6}^{\prime}$ & $s_{7}^{\prime}$ & $s_{8}^{\prime}$ & $s_{9}^{\prime}$ \\
\hline$s_{0}$ & 1.0 & 0.0 & 0.0 & 0.0 & 0.0 & 0.0 & 0.0 & 0.0 & 0.0 & 0.0 \\
\hline$s_{1}$ & 0.0007 & 0.8677 & 0.1317 & 0.0 & 0.0 & 0.0 & 0.0 & 0.0 & 0.0 & 0.0 \\
\hline$s_{2}$ & 0.038 & 0.1384 & 0.82 & 0.0036 & 0.0 & 0.0 & 0.0 & 0.0 & 0.0 & 0.0 \\
\hline$s_{3}$ & 0.0 & 0.0 & 0.0071 & 0.98 & 0.0129 & 0.0 & 0.0 & 0.0 & 0.0 & 0.0 \\
\hline$s_{4}$ & 0.0 & 0.0 & 0.0 & 0.0223 & 0.953 & 0.0247 & 0.0 & 0.0 & 0.0 & 0.0 \\
\hline$s_{5}$ & 0.0 & 0.0 & 0.0 & 0.0 & 0.0529 & 0.94 & 0.0071 & 0.0 & 0.0 & 0.0 \\
\hline$s_{6}$ & 0.0 & 0.0 & 0.0 & 0.0 & 0.0 & 0.0165 & 0.971 & 0.0125 & 0.0 & 0.0 \\
\hline$s_{7}$ & 0.0 & 0.0 & 0.0 & 0.0 & 0.0 & 0.0 & 0.0414 & 0.95 & 0.0086 & 0.0 \\
\hline$s_{8}$ & 0.0 & 0.0 & 0.0 & 0.0 & 0.0 & 0.0 & 0.0 & 0.022 & 0.955 & 0.023 \\
\hline$s_{9}$ & 0.0 & 0.0 & 0.0 & 0.0 & 0.0 & 0.0 & 0.0 & 0.0 & 0.024 & 0.976 \\
\hline
\end{tabular}




\section{Table 4}

Business Cycles (HP smoothing parameter $=1,600)$

\begin{tabular}{|c|c|c|c|c|c|c|}
\hline \multicolumn{7}{|c|}{ Panel A: Data (1951:1-2004:4) } \\
\hline \multicolumn{7}{|c|}{ Standard deviations } \\
\hline & $\mathrm{Y}$ & $\mathrm{N}$ & $\mathrm{U}$ & $\mathrm{A}$ & $\mathrm{A} / \mathrm{U}$ & $\mathrm{Y} / \mathrm{N}$ \\
\hline & 1.58 & 1.00 & 12.32 & 13.95 & 25.71 & 0.99 \\
\hline \multicolumn{7}{|c|}{ Correlations } \\
\hline & $\mathrm{Y}$ & $\mathrm{N}$ & $\mathrm{U}$ & $\mathrm{A}$ & $\mathrm{A} / \mathrm{U}$ & $\mathrm{Y} / \mathrm{N}$ \\
\hline $\mathrm{Y}$ & 1.00 & 0.81 & -0.84 & 0.90 & 0.89 & 0.79 \\
\hline $\mathrm{N}$ & & 1.00 & -0.87 & 0.88 & 0.89 & 0.26 \\
\hline $\mathrm{U}$ & & & 1.00 & -0.91 & -0.98 & -0.46 \\
\hline $\mathrm{A}$ & & & & 1.00 & 0.98 & 0.54 \\
\hline $\mathrm{A} / \mathrm{U}$ & & & & & 1.00 & 0.51 \\
\hline $\mathrm{Y} / \mathrm{N}$ & & & & & & 1.00 \\
\hline \multicolumn{7}{|c|}{ Panel B: Model w/externalities (linear preferences) } \\
\hline \multicolumn{7}{|c|}{ Standard deviations } \\
\hline & $\mathrm{Y}$ & $\mathrm{N}$ & $\mathrm{U}$ & $\mathrm{A}$ & $\mathrm{A} / \mathrm{U}$ & $\mathrm{Y} / \mathrm{N}$ \\
\hline & 1.51 & 0.84 & 11.78 & 11.82 & 22.11 & 0.76 \\
\hline \multicolumn{7}{|c|}{ Correlations } \\
\hline & Y & $\mathrm{N}$ & $\mathrm{U}$ & $\mathrm{A}$ & $\mathrm{A} / \mathrm{U}$ & $\mathrm{Y} / \mathrm{N}$ \\
\hline $\mathrm{Y}$ & 1.00 & 0.95 & -0.93 & 0.85 & 0.95 & 0.94 \\
\hline $\mathrm{N}$ & & 1.00 & -0.99 & 0.71 & 0.91 & 0.77 \\
\hline $\mathrm{U}$ & & & 1.00 & -0.75 & -0.94 & -0.75 \\
\hline $\mathrm{A}$ & & & & 1.00 & 0.93 & 0.90 \\
\hline $\mathrm{A} / \mathrm{U}$ & & & & & 1.00 & 0.89 \\
\hline $\mathrm{Y} / \mathrm{N}$ & & & & & & 1.00 \\
\hline
\end{tabular}




\section{Table 5}

Steady state results

\begin{tabular}{c||c|c||c|c}
\hline \multicolumn{1}{c||}{} & \multicolumn{2}{c||}{ Linear Preferences } & \multicolumn{2}{c}{ Log Preferences } \\
\cline { 2 - 5 } & Externalities & Efficiency & Externalities & Efficiency \\
\hline \hline \multirow{2}{*}{ output } & 100.0 & 93.8 & 100.0 & 95.6 \\
consumption & 100.0 & 94.5 & 100.0 & 96.3 \\
employment & 100.0 & 90.1 & 100.0 & 93.0 \\
unemployment & 100.0 & 227.6 & 100.0 & 190.9 \\
vacancies & 100.0 & 18.9 & 100.0 & 23.3 \\
matches & 100.0 & 113.4 & 100.0 & 105.9 \\
vacancies/unemployment & 100.0 & 8.3 & 100.0 & 12.2 \\
output/employment & 100.0 & 104 & 100.0 & 102.8 \\
quarterly JGB & $1.6 \%$ & $1.7 \%$ & $1.6 \%$ & $1.6 \%$ \\
quarterly JBE & $6.2 \%$ & $7.4 \%$ & $6.2 \%$ & $6.9 \%$ \\
quarterly JLD & $1.6 \%$ & $1.7 \%$ & $1.6 \%$ & $1.6 \%$ \\
quarterly JLC & $6.2 \%$ & $7.4 \%$ & $6.2 \%$ & $6.9 \%$ \\
vacancies tax rate & $0.0 \%$ & $257 \%$ & $0.0 \%$ & $257 \%$ \\
UI replacement ratio & $0.0 \%$ & $4.4 \%$ & $0.0 \%$ & $6.5 \%$ \\
Steady state welfare gains & $0.0 \%$ & $0.8 \%$ & $0.0 \%$ & $0.7 \%$ \\
\hline \hline
\end{tabular}




\section{FIGURE 1}

Transitionary dynamics (linear preferences)

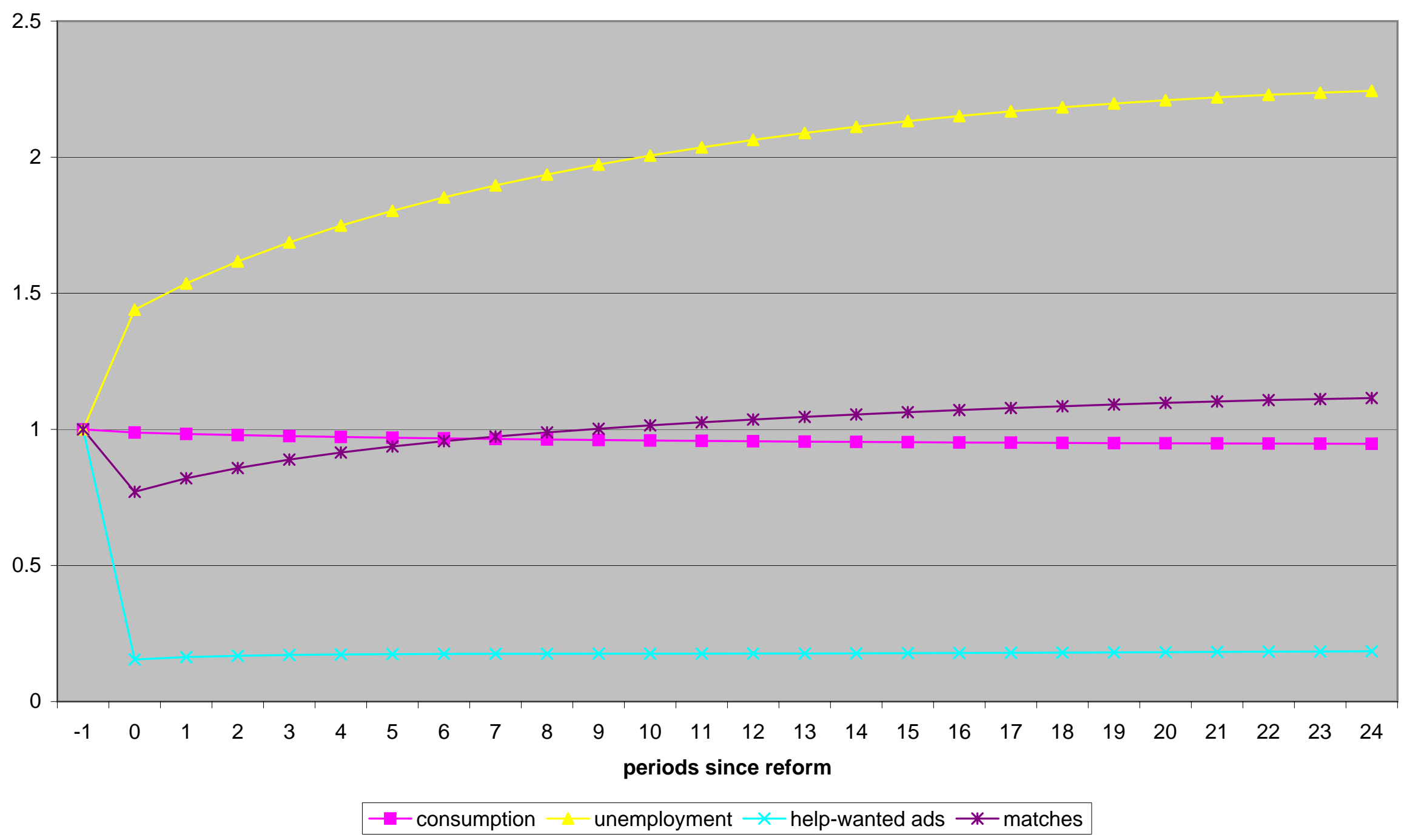




\section{Table 6}

Welfare effects

\begin{tabular}{c||c|c||c|c}
\hline \hline \multicolumn{1}{c||}{} & \multicolumn{2}{c||}{ Linear Preferences } & \multicolumn{2}{c}{ Log Preferences } \\
\cline { 2 - 5 } & Externalities & Efficiency & Externalities & Efficiency \\
\hline \hline Steady state welfare gains & $0.0 \%$ & $0.8 \%$ & $0.0 \%$ & $0.7 \%$ \\
Transitionary dynamics welfare gains & $0.0 \%$ & $1.1 \%$ & $0.0 \%$ & $1.1 \%$ \\
\hline \hline
\end{tabular}




\section{Table 7}

Business Cycles Effects of Optimal Policy (Linear preferences)

\begin{tabular}{|c|c|c|c|c|c|c|}
\hline \multicolumn{7}{|c|}{ Panel A: Externalities } \\
\hline \multicolumn{7}{|c|}{ Standard deviations } \\
\hline & $\mathrm{Y}$ & $\mathrm{N}$ & $\mathrm{U}$ & $\mathrm{A}$ & $\mathrm{A} / \mathrm{U}$ & $\mathrm{Y} / \mathrm{N}$ \\
\hline & 1.51 & 0.84 & 11.78 & 11.82 & 22.11 & 0.76 \\
\hline \multicolumn{7}{|c|}{ Correlations } \\
\hline & $\mathrm{Y}$ & $\mathrm{N}$ & $\mathrm{U}$ & $\mathrm{A}$ & $\mathrm{A} / \mathrm{U}$ & $\mathrm{Y} / \mathrm{N}$ \\
\hline $\mathrm{Y}$ & 1.00 & 0.95 & -0.93 & 0.85 & 0.95 & 0.94 \\
\hline $\mathrm{N}$ & & 1.00 & -0.99 & 0.71 & 0.91 & 0.77 \\
\hline $\mathrm{U}$ & & & 1.00 & -0.75 & -0.94 & -0.75 \\
\hline $\mathrm{A}$ & & & & 1.00 & 0.93 & 0.90 \\
\hline $\mathrm{A} / \mathrm{U}$ & & & & & 1.00 & 0.89 \\
\hline $\mathrm{Y} / \mathrm{N}$ & & & & & & 1.00 \\
\hline \multicolumn{7}{|c|}{ Panel B: Efficiency } \\
\hline \multicolumn{7}{|c|}{ Standard deviations } \\
\hline & $\mathrm{Y}$ & $\mathrm{N}$ & $\mathrm{U}$ & $\mathrm{A}$ & $\mathrm{A} / \mathrm{U}$ & $\mathrm{Y} / \mathrm{N}$ \\
\hline & 1.46 & 0.70 & 3.60 & 8.50 & 11.22 & 0.86 \\
\hline \multicolumn{7}{|c|}{ Correlations } \\
\hline & Y & $\mathrm{N}$ & $\mathrm{U}$ & $\mathrm{A}$ & $\mathrm{A} / \mathrm{U}$ & $\mathrm{Y} / \mathrm{N}$ \\
\hline $\mathrm{Y}$ & 1.00 & 0.92 & -0.92 & 0.91 & 0.98 & 0.95 \\
\hline $\mathrm{N}$ & & 1.00 & -1.00 & 0.67 & 0.83 & 0.75 \\
\hline $\mathrm{U}$ & & & 1.00 & -0.67 & -0.83 & -0.75 \\
\hline $\mathrm{A}$ & & & & 1.00 & 0.97 & 0.99 \\
\hline $\mathrm{A} / \mathrm{U}$ & & & & & 1.00 & 0.99 \\
\hline $\mathrm{Y} / \mathrm{N}$ & & & & & & 1.00 \\
\hline
\end{tabular}

